\title{
Plutonium Immobilization Project Binder Burnout and Sintering Studies (Milestone 6.6a)
}

by

G. Chandler

Westinghouse Savannah River Company

Savannah River Site

Aiken, South Carolina 29808
A. Cozzi
c. Herman

J. Mara

M. Mitchell

LLNL

R. Pierce

DOE Contract No. DE-AC09-96SR18500

This paper was prepared in connection with work done under the above contract number with the U.S.

Department of Energy. By acceptance of this paper, the publisher and/or recipient acknowledges the U.S. Government's right to retain a nonexclusive, royalty-free license in and to any copyright covering this paper, along with the right to reproduce and to authorize others to reproduce all or part of the copyrighted paper. 
WSRC-TR-99-00321

Rev 0

Keywords:

PIP

Pu ceramic pucks

Phase development

Binder burnout

Sintering schedule

\title{
Plutonium Immobilization Program (PIP) \\ Binder Burnout and Sintering Studies
}

(PIP Milestone 6.6a)

\author{
Greg Chandler, WSRC \\ Alex Cozzi, WSRC \\ Connie Herman, WSRC/LLNL \\ James Marra, WSRC \\ Mark Mitchell, LLNL \\ Robert Pierce, WSRC \\ Savannah River Technology Center \\ and Lawrence Livermore National Laboratory
}

Date: October 6, 1999

\author{
UNCLASSIFIED \\ DOES NOT CONTAIN \\ UNCLASSIFIED CONTROLLED \\ NUCLEAR INFORMATION
}

ADC \&

Reviewing Official: Eatbetzahule

Date: $10-11.99$

Westinghouse Savannah River Company

Savannah River Site

Aiken, SC 29808 


\section{DISCLAIMER}

This report was prepared as an account of work sponsored by an agency of the United States Government. Neither the United States Government nor any agency thereof, nor any of their employees, makes any warranty, express or implied, or assumes any legal liability or responsibility for the accuracy, completeness, or usefulness of any information, apparatus, product, or process disclosed, or represents that its use would not infringe privately owned rights. Reference herein to any specific commercial product, process, or service by trade name, trademark, manufacturer, or otherwise does not necessarily constitute or imply its endorsement, recommendation, or favoring by the United States Government or any agency thereof. The views and opinions of authors expressed herein do not necessarily state or reflect those of the United States Government or any agency thereof.

This report has been reproduced directly from the best available copy.

Available to DOE and DOE contractors from the Office of Scientific and Technical Information, P.O. Box 62, Oak Ridge, TN 37831; prices available from (615) 576-8401.

Available to the public from the National Technical Information Service, U.S. Department of Commerce, 5285 Port Royal Road, Springfield, VA 22161. 


\section{DISCLAIMER}

Portions of this document may be illegible in electronic image products. Images are produced from the best available original document. 
October 6, 1999

WSRC-TR-99-00321

Rev. 0

APPROVALS

7.R. Graham for ALB/ancett

Allen Blancett, Level 3 Manager

WSRC / SRTC / Actinide Technology Section

Games C. Maun on DT Rankin

D. Thomas Rankin, Plutonium Immobilization Technical Lead WSRC / SRTC / Actinide Technology Section $\frac{10 / 6 / 99}{\text { Date }}$

$\frac{10 / 11 / 99}{\text { Date }}$

$\frac{10 / 6 / 1999}{\text { Date }}$

$10 / 6 / 99$

Date

$\frac{10 / 6 / 99}{\text { Date }}$

$\frac{10 / 2 / 99}{\text { Date }}$

$\frac{10 / 6 / 99}{\text { Date }}$

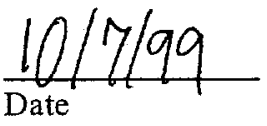

$\frac{10 / 6 / 99}{\text { Date }}$

Robert Pierce, Author

WSRC / SRTC / Actinide Technology Section 
TABLE OF CONTENTS

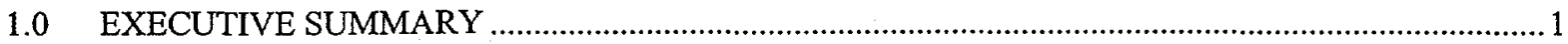

2.0 INTRODUCTION

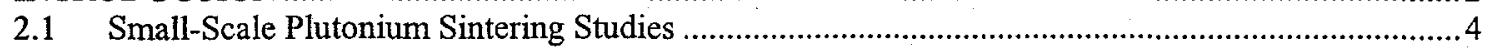

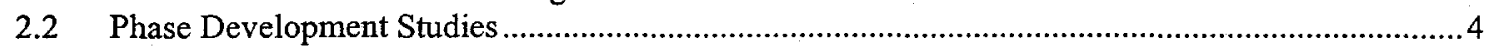

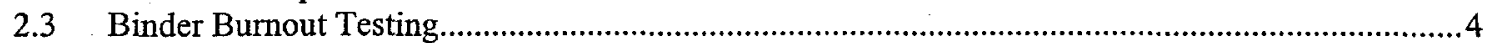

2.4 Clemson Prototypic Test Facility and LLNL Pu Cermamification Test Facility ..............................

2.5 Process Development Status .............................................................................................................

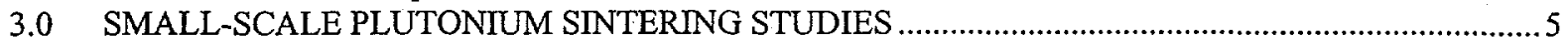

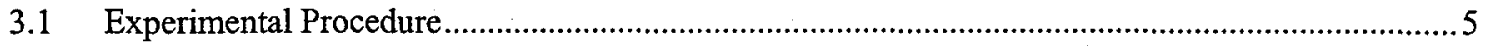

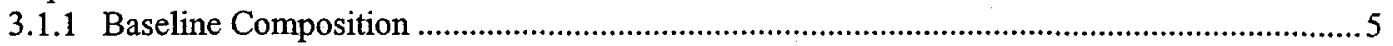

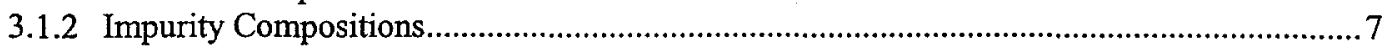

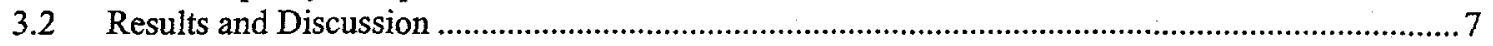

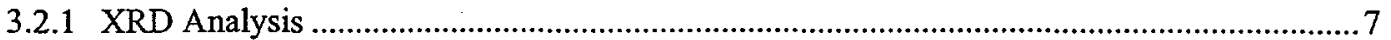

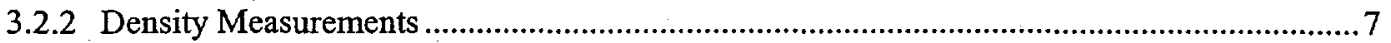

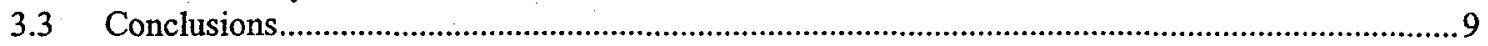

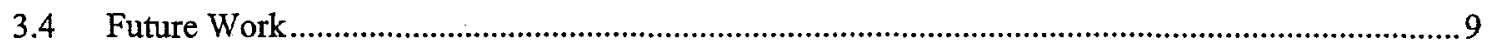

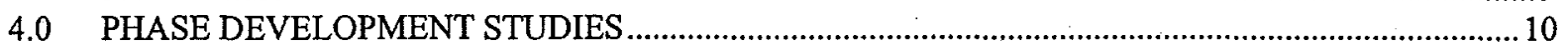

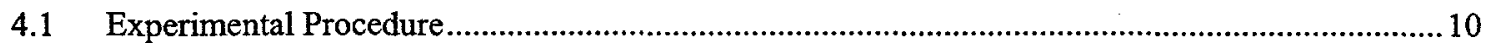

4.1.1 Initial Thermal Analysis and Isothermal Heat Treatments ................................................ 10

4.1.2 High Temperature X-ray Diffraction ……..................................................................... 10

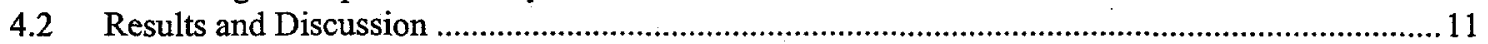

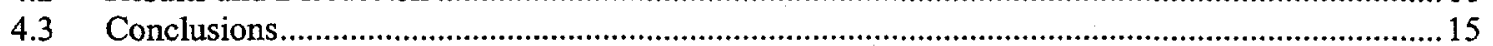

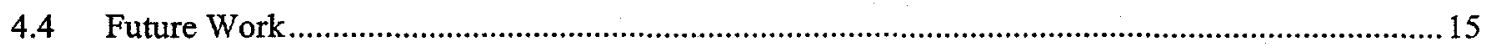

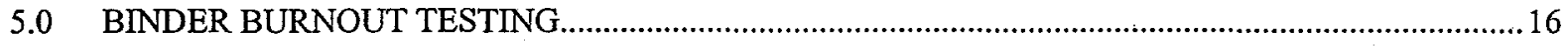

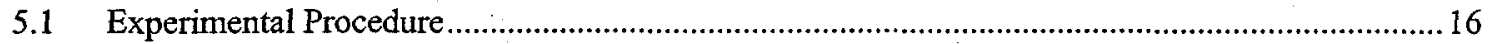

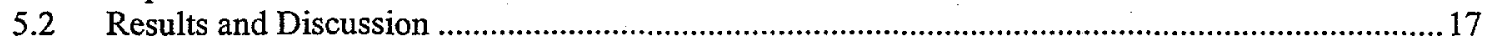

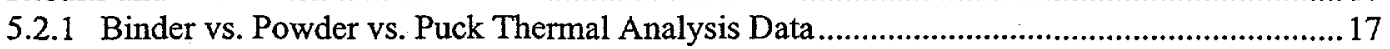

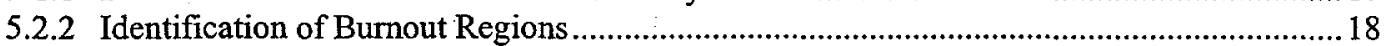

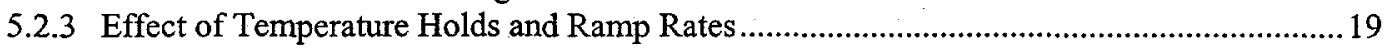

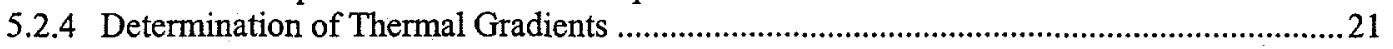

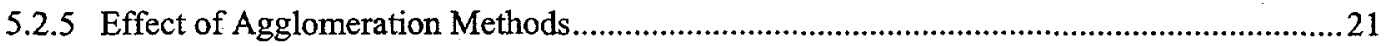

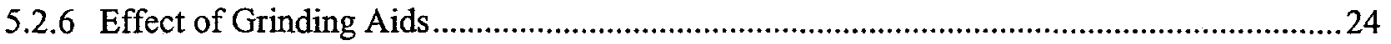

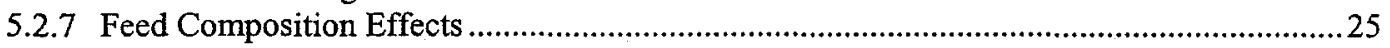

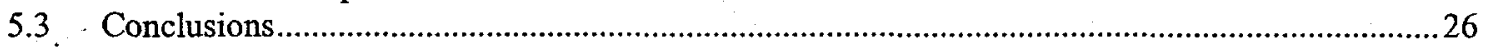

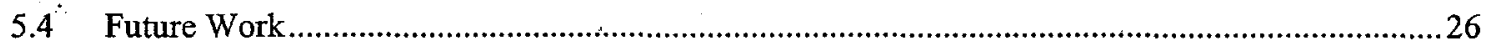

6.0 CLEMSON PROTOTYPIC TEST FACILITY AND LLNL PU CERAMIFICATION

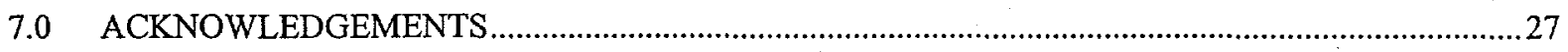

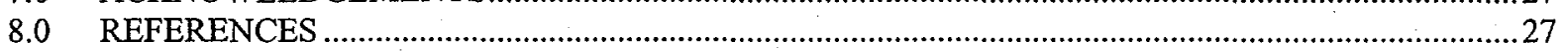

APPENDIX A Weight Loss Data from Preliminary TGA Studies of Binder Only and Binder + Precursor Powders .........................................................29

APPENDIX B Weight Loss Data From

Binder Burnout Testing Performed To Date …............................................................ 31 


\section{List of Tables}

Table 2.1 Baseline Composition for Pu Immobilized Form .........................................................................

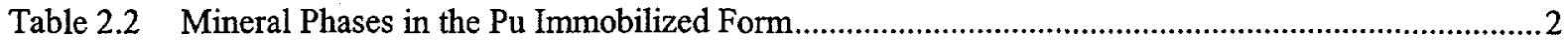

Table 3.1 Baseline Composition (A-0) for Pu Immobilized Form ..................................................................5

Table 3.2 Pu Baseline Composition Sintering Study Matrix …................................................................

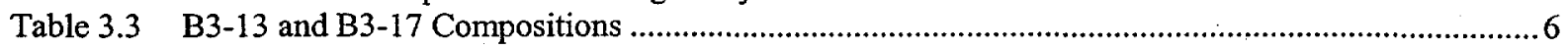

Table 3.4 XRD Analysis of Sintered Pellets (Pu, U) ................................................................................

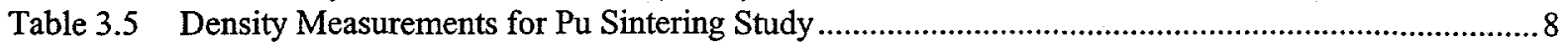

Table 4.1 Phase Assemblages of Isothermally Heated Samples .....................................................................11

Table 5.1 Comparison of Burnout Behavior of Baseline Material ...................................................................18

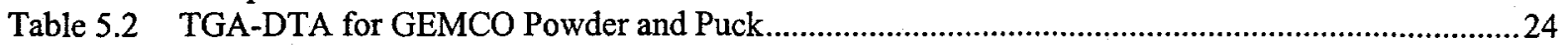

Table 5.3 TGA-DTA for Ball Milled versus Attritor Milled Powder .........................................................25

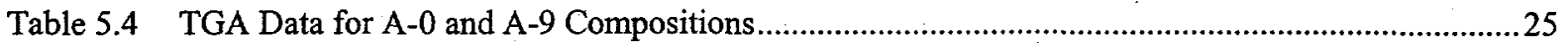

\section{List of Figures}

Figure 4.1 DTA and TGA of reagent grade $\mathrm{Ca}(\mathrm{OH})_{2}$ showing the decomposition of $\mathrm{Ca}(\mathrm{OH})_{2}$, in-growth of $\mathrm{CaCO}_{3}$ and decomposition of $\mathrm{CaCO}_{3}$.

Figure 4.2. Intensity of the major $\mathrm{Ca}(\mathrm{OH})_{2}$ diffraction peak vs. time for reagent grade $\mathrm{Ca}(\mathrm{OH})_{2}$ indicating the rapid decomposition of calcium hydroxide at $400^{\circ} \mathrm{C}$.

Figure 4.3. Intensity of the major $\mathrm{CaCO}_{3}$ diffraction peak vs. time for reagent grade $\mathrm{Ca}(\mathrm{OH})_{2}$ indicating the in-growth of $\mathrm{CaCO}_{3}$ at $450^{\circ} \mathrm{C}$.

Figure 4.4. Formation of perovskite in the baseline surrogate composition at $1000^{\circ} \mathrm{C}$. Rapid in-growth occurs which quickly reaches a saturation concentration as indicated by little increase in peak intensity with increasing time.

Figure 4.5. Formation of pyrochlore in the baseline surrogate composition at $1000^{\circ} \mathrm{C}$. The pyrochlore concentration increases more gradually with increasing time.

Figure 4.6. Dilatometry scan of baseline ceramic formulation. Batch was calcined at

Figure 5.1. Baseline binder burnout of a full-size puck produced with wet ball milled

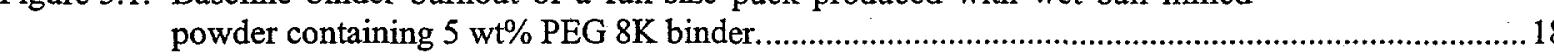

Figure 5.2. Binder burnout offgassing regions..................................................................................... 19

Figure 5.3. Low temperature hold (dehydration) experiments on pucks pressed from

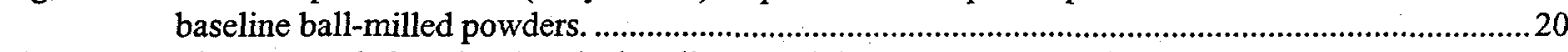

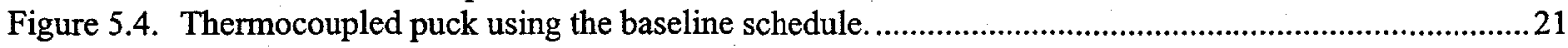

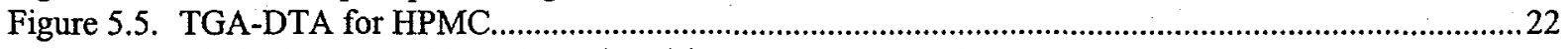

Figure 5.6. Binder burnout with puck produced from GEMCO powder. ...............................................................22

Figure 5.7. Offgas behavior for puck produced from GEMCO powder. ..............................................................23

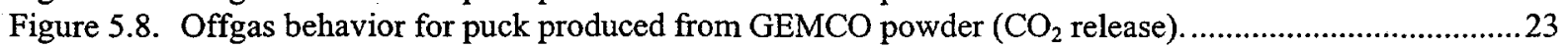




\subsection{EXECUTIVE SUMMARY}

The Plutonium Immobilization Team has developed an integrated test program to understand and optimize the controlling variables for the sintering step of the plutonium immobilization process. Sintering is the key process step that controls the product minerology. It is expected that the sintering will be the limiting process step that controls the throughput of the production line. Therefore, optimization of the sintering step is important for overall success of the project. A preliminary, baseline sintering schedule for an air atmosphere was developed as follows:

- $\quad$ heat at $3^{\circ} \mathrm{C} / \mathrm{min}$ to $300^{\circ} \mathrm{C}$,

- 2 hour hold at $300^{\circ} \mathrm{C}$ for binder burnout,

- heat at $5^{\circ} \mathrm{C} / \mathrm{min}$ to $1350^{\circ} \mathrm{C}$,

- hold at $1350^{\circ} \mathrm{C}$ for 4 hours, and

- $\quad \operatorname{cool}$ at $5^{\circ} \mathrm{C} / \mathrm{min}$ to room temperature.

The goal of the current sintering test program is to better understand factors that affect the sintering process. The program test elements include 1) small-scale plutonium sintering studies, 2) phase development studies, 3) binder burnout testing, and 4) prototype testing. The following major conclusions can be drawn from the data obtained thus far:

Based on small-scale plutonium sintering studies:

1) Sintering temperatures ranging from $1275^{\circ} \mathrm{C}$ to $1375^{\circ} \mathrm{C}$ in air produce the proper phase assemblages with baseline composition powders. However, a longer sintering time at the lower temperature of $1275^{\circ} \mathrm{C}$ is required to achieve complete incorporation of $\mathrm{UO}_{2}$ into the proper phases.

2) Dimensional shrinkage of pellets produced from wet ball-milled powder ranged from $21-25 \%$ over the range of sintering temperatures of $1275-1375^{\circ} \mathrm{C}$ for baseline and impurity compositions. This range is consistent with full-size puck testing with Ce substituted for $\mathrm{Pu}$.

3) Initial studies with B3-13 and B3-17 impurity compositions indicate that partial macroscopic melting and formation of a glass phase occurs at a sintering temperature of $1350^{\circ} \mathrm{C}$ for 4 hours. The macroscopic melting was not observed in pellets sintered at $1300^{\circ} \mathrm{C}$ for 4 hours. These results are consistent with studies performed on full-size puck testing at the LLNL Pu facility and provides the first, consistent tie-in with the full-scale $\mathrm{Pu}$ puck testing. Therefore, the limiting maximum sintering temperature for impurity compositions will most likely be based on minimizing the flow of a low viscosity glass phase from the matrix.

Based on phase development and binder burnout studies:

1) Critical burnout temperature regions were defined for the sintering process using key thermal analysis tools including thermogravimetric analysis (TGA), differential thermal analysis (DTA), high temperature x-ray diffraction (HT-XRD), dilatometry, and binder burnout - Fourier transform infrared spectroscopy (BBO-FTIR). Final puck integrity is dependent upon proper control of heating rates and critical temperatures in these regions.

2) Phase formation studies have also identified temperature ranges corresponding to phase assemblage development.

3) Process parameters (e.g. granulation methods, pressing pressure, binder dispersal, and binder type, etc.) have an important influence on puck offgassing behavior and, thus, the binder burnout schedule and puck integrity.

4) Optimization of the burnout regions (i.e. determination of the maximum heating rates, proper low temperature holds and minimum soak times to ensure product quality) can be accomplished using the demonstrated thermal analysis tools once binder selection is made.

Based on studies to date, the full-scale furnace for the Clemson Prototypic Test Facility should be designed to operate at a nominal sintering temperature range of $1275-1400^{\circ} \mathrm{C}$. The maximum furnace temperature capability should be designed in the range of $1600-1700^{\circ} \mathrm{C}$ to provide adequate margin between the expected normal operating sintering temperature and maximum capability. The furnace should also be designed to meet the current baseline sintering schedule.

To date, the powder processing conditions have not been fully developed. Most recently a tumble granulator was selected as the baseline granulation equipment. Therefore, binder formulations and relative concentrations, as well 
as powder processing steps prior to granulation, are still being developed. Current results of the integrated sintering test program provide important information to aid in the development of the sintering schedule and to ensure that the proper experimental tools have been developed for program success once the powder processing conditions have been fully developed.

\subsection{INTRODUCTION}

The Department of Energy (DOE) plans to immobilize at least some of the excess weapons useable plutonium $(\mathrm{Pu})$ in a ceramic form for final geologic disposal (Ref 1). The preferred immobilization form is a titanate-based ceramic (Ref 2) and the preferred technology is the Can-in-Canister (CIC), or external radiation barrier method (Ref 3). A titanate-based ceramic form or puck, $\sim 6.9 \mathrm{~cm}$ in diameter by $2.5 \mathrm{~cm}$ thick will be loaded with nominally $10 \mathrm{wt} \%$ elemental $\mathrm{Pu}$. Approximately 20 pucks will then be loaded into stainless steel cans. Multiple cans of pucks containing up to $28 \mathrm{~kg} \mathrm{Pu}$ will be encapsulated subsequently in high level waste (HLW) glass within a standard Defense Waste Processing Facility (DWPF) canister. The HLW glass provides a radiation barrier to enhance the proliferation resistance to the Pu pucks.

The proposed immobilization formulation contains chemical precursors to produce a durable ceramic form as well as sufficient neutron absorbers to preclude criticality. The baseline formulation shown in Table 2.1 was designed to produce a ceramic consisting primarily of a highly substituted pyrochlore with minor amounts of brannerite and hafnia-substituted rutile. Many of the prospective feed streams contain large amounts of uranium in addition to plutonium. The pyrochlore phase was shown to readily accommodate significant quantities of actinides (Ref 4$)$. In addition, given that pyrochlore has a cubic structure, it is anticipated that the isotropic nature of the mineral phase will minimize radiation damage. When impurities are present in the $\mathrm{Pu}$ feed streams, other minor phases such as zirconolite, perovskite, glassy phases, etc. may be present in the ceramic form. However, the composition was designed such that all of the phases that contain actinides also have significant amounts of neutron absorbers. Chemical formulas (showing the atomic substitutions) for the various mineral phases observed in the ceramic are shown in Table 2.2.

Table 2.1

Baseline Composition for Pu Immobilized Form

\begin{tabular}{lcl}
\hline Oxide & wt. $\%$ & Role \\
\hline $\mathrm{CaO}$ (added as $\left.\mathrm{Ca}(\mathrm{OH})_{2}\right)$ & 10.0 & Precursor (mineral formation) \\
$\mathrm{TiO}_{2}$ (anatase form) & 35.9 & Precursor (mineral formation) \\
$\mathrm{HfO}_{2}$ & 10.6 & Precursor (mineral formation/neutron absorber) \\
$\mathrm{Gd}_{2} \mathrm{O}_{3}$ & 7.9 & Precursor (neutron absorber) \\
$\mathrm{UO}_{2}$ & 23.7 & Feed material/additive to stabilize pyrochlore \\
$\mathrm{PuO}_{2}$ & 11.9 & Feed material \\
\hline
\end{tabular}

Table 2.2

Mineral Phases in the Pu Immobilized Form

\begin{tabular}{lll}
\hline Mineral Phase & Stoichiometry & Observed range \\
\hline Pyrochlore & $(\mathrm{Ca}, \mathrm{Gd})\left(\mathrm{Hf}, \mathrm{U}, \mathrm{Pu}, \mathrm{Gd}^{2} \mathrm{Ti}_{2} \mathrm{O}_{7}\right.$ & $62-90 \%$ \\
Brannerite & $(\mathrm{U}, \mathrm{Pu}, \mathrm{Hf}, \mathrm{Gd}, \mathrm{Ca}) \mathrm{Ti}_{2} \mathrm{O}_{6}$ & $0-22 \%$ \\
Zirconolite & $(\mathrm{Ca}, \mathrm{Gd})(\mathrm{Hf}, \mathrm{U}, \mathrm{Pu}, \mathrm{Gd}) \mathrm{Ti}_{2} \mathrm{O}_{7}$ & $0-25 \%$ \\
Rutile & $(\mathrm{Ti}, \mathrm{Hf}) \mathrm{O}_{2}$ & $0-16 \%$ \\
Perovskite & $\mathrm{CaTiO}$ & $0-6 \%$ \\
Glassy phase & silica glass & $0-6 \%$ \\
Other minor phases & various & $0-6 \%$ \\
(e.g. monazite) & & \\
\hline
\end{tabular}


Concurrently with formulation development efforts, a ceramic fabrication process is being developed based on cold pressing and sintering. In summary, the current baseline process consists of:

1) milling the actinide oxide feeds to less than $20 \mu \mathrm{m}$ in an attritor mill,

2) micro-scale blending the milled actinide oxides with a commercially supplied precursor batch in a second attritor mill,

3) granulating the conditioned powders,

4) cold pressing the granulated powders into "pucks," and

5) sintering the pressed "pucks."

A baseline sintering schedule has been established in an air atmosphere (Ref 5) for the ceramic form consisting of:

- heating at $3^{\circ} \mathrm{C} / \mathrm{min}$ to $300^{\circ} \mathrm{C}$,

- hold at $300^{\circ} \mathrm{C}$ for 2 hours (h) for binder burnout,

- heating at $5^{\circ} \mathrm{C} / \mathrm{min}$ to $1350^{\circ} \mathrm{C}$,

- hold at $1350^{\circ} \mathrm{C}$ for $4 \mathrm{~h}$, and

- cooling at $5^{\circ} \mathrm{C} / \mathrm{min}$ to room temperature.

As part of the overall development activities for the Plutonium Immobilization Program (PIP), binder burnout and sintering studies are being performed to optimize the sintering process schedule. Final sintered puck acceptance criteria are still in the development stages. However, the sintering step must be developed to meet at least the following requirements:

1) all organic materials must be burned out from the pucks,

2) proper phase mineralogy of the final product must be obtained to ensure product durability,

3) the final product must have acceptable mechanical stability for remote handling, and

4) the cooling and heating rates must minimize thermal stresses in the pucks and kiln furniture (maximize life of kiln furniture).

It is expected that the sintering step of the process will be the limiting process step that controls the throughput of the production line. Therefore, the sintering rate should be as rapid as possible without affecting the quality of the pucks. An integrated test program was developed to better understand the controlling variables in the sintering process to allow optimization of the process. The controlling variables expected to influence the sintering schedule (temperature and time) include the following:

1) particle size of the feed,

2) impurities contained in the feed,

3) calcination temperature of the precursors,

4) type and quantity of organic additives,

5) effectiveness of mixing (oxides and organic additives),

6) physical characteristics of the granules,

7) thermal stress resistance of pucks,

8) moisture content of pucks,

9) green density of pucks,

10) grain boundary limitations (i.e. preventing overheating of grain boundaries), and

11) furnace considerations, including

- effect of full furnace load (pucks and trays) on furnace temperature distribution,

- thermal stress resistance of the trays,

- reactivity of pucks with trays, and

- furnace limitations, such as, cooling rate. 
The sintering program test elements described in this report consist of the following:

\subsection{Small-Scale Plutonium Sintering Studies}

Studies are being performed at SRTC to determine the effect of various sintering temperatures and soak times on phase assemblage and density on small-scale, 1/2" diameter pellets pressed from baseline and impurity compositions with $\mathrm{PuO}_{2}$ and $\mathrm{UO}_{2}$. The goal of the study is to determine a range of acceptable temperatures and times to produce proper phase mineralogy, determine the effect of sintering schedules on density, and minimize kiln furniture interactions. As part of this study, various candidate kiln furniture materials are being evaluated.

\subsection{Phase Development Studies}

Unlike solid state or single phase sintering processes, the sintering of the Pu immobilized ceramic form is "reactive" in nature, where the oxide precursors react to form highly substituted mineral phases. To date, little is known about the reactions that occur and their progression. The objective of the phase development studies is to identify reactions and reaction temperatures occurring in the ceramic formulation to understand phase development progression in the ceramic. Thermal analysis studies performed at SRTC and the Clemson University - Ceramic and Materials Engineering Department were coupled with $\mathrm{x}$-ray diffraction analysis (XRD) performed at SRTC to identify reaction temperatures and mechanisms occurring during the heating process.

\subsection{Binder Burnout Testing}

The Plutonium Immobilization Product Specifications (PIPS) and the Waste Acceptance Product Specifications (WAPS) require the producer to ensure that the canistered waste form does not contain detectable amounts of organic materials (Ref 6,7 ). Therefore, complete burnout of the organic materials during the sintering step is required. In addition, proper controls during binder burnout are necessary to ensure that water, organic products, and any other volatiles contained in the puck are easily removed without damaging the puck integrity.

Binder burnout is strongly dependent on the upstream ceramic processes and the composition of the final green puck. Upstream processes include the preparation of the precursors (e.g., choice of raw materials, impurities, and the calcination temperature), the mixing process (e.g., ball milling or attritor milling), the granulation process (e.g., type of granulation equipment, the binder dispersion method, and the type and quantity of binder), and the pressing parameters (e.g., compaction pressure). The particle size of the material resulting from these processes and the composition of the feed material has also been shown to indirectly affect the binder burnout process.

Initial thermal analysis studies were performed at SRTC and LLNL on various feed powders with and without binders and grinding aids to provide basic information on organic burnout temperature ranges and behavior. These studies provided input to large-scale binder burnout tests performed at LLNL. A large-scale binder burnout test apparatus with an online Fourier Transform Infrared Spectroscopy (BBO-FTIR) system was developed at LLNL to provide a better understanding of the effect of these variables on the binder burnout process and to optimize the burnout schedule. These data are being correlated with other thermal analysis studies performed at SRTC, LLNL, and ANSTO. BBO-FTIR testing has produced techniques to control offgassing and ensure product quality.

\subsection{Clemson Prototypic Test Facility and LLNL Pu Cermamification Test Facility}

A prototype process test facility is currently being designed for the Clemson Environmental Technology Laboratory (CETL) to perform full-scale testing of the ceramic system using surrogate materials to confirm and optimize the physical process operations. This capability is needed to ensure that the as-designed plant equipment will effectively condition, press, and sinter oxide powders in the configuration intended for the immobilization plant. Data obtained from the current sintering studies are being used to design the prototype sintering furnace for the CETL. Full-load testing (pucks and furnace trays) with the prototypical sintering furnace will aid in validating and optimizing the sintering schedule.

Testing of full-size plutonium pucks will also be performed at the LLNL Pu Ceramification Test Facility (PuCTF). In the PuCTF, the critical ceramic processing steps will be coupled, optimized, and demonstrated using subproduction scale, but functionally prototypic, equipment. The PuCTF will couple subscale milling, micro-scale 
blending, and granulation equipment for the actinide milling and blending operations with a full-scale automated press and a laboratory-scale sintering furnace. The equipment in this integrated glovebox system will be used to confirm critical operations and to assess maintenance issues (powder transfer, dust control, material hold-up, material accountability, operator radiation dose control).

\subsection{Process Development Status}

To date, the powder processing conditions have not been fully developed. Most recently a tumble granulator was selected as the baseline granulation equipment. Therefore, binder formulations and relative concentrations as well as powder processing steps prior to granulation are still being developed. Since the sintering characteristics of the product is highly dependent upon the powder process conditions, a fully defined and optimized sintering schedule cannot be reported based on the current sintering studies. However, the studies do provide important information to aid in the development of the sintering schedule and to ensure that the proper experimental tools have been developed for program success once the powder processing conditions have been fully developed. The current and future results of the sintering test program elements will be integrated with form and process development activities to optimize the sintering schedule. The following provides data from the current sintering program elements, conclusions that can be drawn from the current data, and future work that needs to be performed.

\subsection{SMALL-SCALE PLUTONIUM SINTERING STUDIES}

\subsection{Experimental Procedure}

\subsubsection{Baseline Composition}

Small-scale plutonium sintering studies have been performed at SRTC. A $60 \mathrm{~g}$ batch of the baseline composition (A-0) shown in Table 3.1 was prepared for the plutonium sintering study. The non-radioactive precursors were wet ball-milled in a polypropylene bottle filled approximately half full with $3 / 8$ " zirconia grinding media for approximately 20 hours. The $\mathrm{PuO}_{2}$ powder was formed by calcining plutonium oxalate at $1000^{\circ} \mathrm{C}$ for two hours in air in a platinum crucible. The $\mathrm{PuO}_{2}$ and $\mathrm{UO}_{2}$ powders were added to the milled precursors and then the resulting slurry was milled for an additional 8 hours. The powder was separated from the grinding media, dried at $110^{\circ} \mathrm{C}$, and then forced through a sieve with 2-mm openings using a stainless steel roller. Pellets were pressed from nominally $1.8 \mathrm{~g}$ of powder using a $1 / 2$ " diameter die and using a 2000 -pound load $(\sim 10 \mathrm{ksi})$ with a dwell time of $5-10$ seconds. The pellets were heated in air to the specified sintering temperature at $5^{\circ} \mathrm{C} / \mathrm{min}$, held at the sintering temperature for the specified time, cooled to $<1000^{\circ} \mathrm{C}$ at $5^{\circ} \mathrm{C} / \mathrm{min}$, and then furnace cooled to room temperature. The sintering temperatures ranged from $1275^{\circ} \mathrm{C}$ to $1375^{\circ} \mathrm{C}$. Table 3.2 shows a matrix of the baseline composition sintering study. Two to three pellets were produced for each condition. Geometric density measurements were performed on all pellets and Archimedes measurements were performed on selected pellets. The surface of one pellet from each condition was analyzed by X-Ray Diffraction (XRD). The pellet was then ground and the resultant powder was analyzed by XRD to obtain a bulk composition.

Table 3.1

Baseline Composition (A-0) for Pu Immobilized Form

\begin{tabular}{lr}
\hline Oxide & wt.\% \\
\hline $\mathrm{CaO}$ (added as $\left.\mathrm{Ca}(\mathrm{OH})_{2}\right)$ & 10.0 \\
$\mathrm{TiO}_{2}$ (anatase form) & 35.9 \\
$\mathrm{HfO}_{2}$ & 10.6 \\
$\mathrm{Gd}_{2} \mathrm{O}_{3}$ & 7.9 \\
$\mathrm{UO}_{2}$ & 23.7 \\
$\mathrm{PuO}_{2}$ & 11.9 \\
\hline
\end{tabular}


Table 3.2

Pu Baseline Composition Sintering Study Matrix

\begin{tabular}{cc}
\hline Sintering Temperature & Sintering Time \\
\hline $1275^{\circ} \mathrm{C}$ & $4 \mathrm{hrs}$ \\
$1275^{\circ} \mathrm{C}$ & $6 \mathrm{hrs}$ \\
$1300^{\circ} \mathrm{C}$ & $4 \mathrm{hrs}$ \\
$1300^{\circ} \mathrm{C}$ & $6 \mathrm{hrs}$ \\
$1325^{\circ} \mathrm{C}$ & $4 \mathrm{hrs}$ \\
$1350^{\circ} \mathrm{C}$ & $2 \mathrm{hrs}$ \\
$1350^{\circ} \mathrm{C}$ & $4 \mathrm{hrs}$ \\
$1375^{\circ} \mathrm{C}$ & $2 \mathrm{hrs}$ \\
\hline
\end{tabular}

Table 3.3

B3-13 and B3-17 Compositions

\begin{tabular}{|c|c|c|}
\hline Oxide & $\begin{array}{c}\text { B3-13 } \\
\text { wt } \% \\
\end{array}$ & $\begin{array}{c}\text { B3-17 } \\
w t \% \\
\end{array}$ \\
\hline $\mathrm{CaO}$ (added as $\left.\mathrm{Ca}(\mathrm{OH})_{2}\right)$ & 8.300 & 7.920 \\
\hline $\mathrm{TiO}_{2}$ (anatase form) & 33.804 & 32.461 \\
\hline $\mathrm{HfO}_{2}$ & 10.270 & 9.643 \\
\hline $\mathrm{Gd}_{2} \mathrm{O}_{3}$ & 7.519 & 7.197 \\
\hline $\mathrm{UO}_{2}$ & 22.312 & 21.443 \\
\hline $\mathrm{PuO}_{2}$ & 11.200 & 10.764 \\
\hline $\mathrm{Al}_{2} \mathrm{O}_{3}$ & 0.723 & 2.437 \\
\hline $\mathrm{B}_{2} \mathrm{O}_{3}$ (added as $\mathrm{H}_{3} \mathrm{BO}_{3}$ ) & 0.101 & 0.176 \\
\hline $\mathrm{BaO}$ (added as $\mathrm{BaCO}_{3}$ ) & 0.143 & 0.122 \\
\hline $\mathrm{CaCl}_{2}$ (added as $\mathrm{CaCl}_{2} * 2 \mathrm{H}_{2} \mathrm{O}$ ) & 0.667 & 1.114 \\
\hline $\mathrm{CeO}_{2}$ & 0.184 & 0.144 \\
\hline $\mathrm{Cr}_{2} \mathrm{O}_{3}$ & 0.050 & 0.151 \\
\hline $\mathrm{Cu}_{2} \mathrm{O}_{3}$ (added as $\mathrm{CuO}$ ) & 0.117 & 0.000 \\
\hline $\mathrm{CaF}_{2}$ & 1.025 & 0.731 \\
\hline $\mathrm{FeO}$ (added as $\mathrm{Fe}_{2} \mathrm{O}_{3}$ ) & 0.187 & 0.513 \\
\hline $\mathrm{Ga}_{2} \mathrm{O}_{3}$ & 0.387 & 0.000 \\
\hline $\mathrm{K}_{2} \mathrm{O}$ (added as $\mathrm{K}_{2} \mathrm{CO}_{3}$ ) & 0.225 & 0.962 \\
\hline $\mathrm{La}_{2} \mathrm{O}_{3}$ & 0.017 & 0.024 \\
\hline $\mathrm{MgO}$ & 0.433 & 0.979 \\
\hline $\mathrm{MoO}_{2}$ (added as $\mathrm{MoO}_{3}$ ) & 0.161 & 0.175 \\
\hline $\mathrm{Na}_{2} \mathrm{O}$ (added as $\mathrm{Na}_{2} \mathrm{CO}_{3}$ ) & 0.232 & 0.388 \\
\hline $\mathrm{NiO}$ & 0.086 & 0.292 \\
\hline $\mathrm{Nd}_{2} \mathrm{O}_{3}$ & 0.291 & 0.000 \\
\hline $\mathrm{P}_{2} \mathrm{O}_{5}$ & 0.006 & 0.000 \\
\hline $\mathrm{PbO}$ & 0.516 & 0.000 \\
\hline $\mathrm{SiO}_{2}$ & 0.880 & 2.139 \\
\hline $\mathrm{SnO}_{2}$ & 0.006 & 0.000 \\
\hline $\mathrm{Ta}_{2} \mathrm{O}_{5}$ & 0.080 & 0.224 \\
\hline $\mathrm{WO}_{2}$ (added as $\mathrm{WO}_{3}$ ) & 0.017 & 0.000 \\
\hline $\mathrm{ZnO}$ & 0.060 & 0.000 \\
\hline
\end{tabular}




\subsubsection{Impurity Compositions}

Sintering studies were also performed on impurity compositions B3-13 and B3-17. Table 3.3 shows the nominal compositions of B3-13 and B3-17. The powders were processed in the same manner as the A-0 baseline material in $12.5 \mathrm{~g}$ batches. Two pellets from each composition were sintered at $1350^{\circ} \mathrm{C}$ and $1300^{\circ} \mathrm{C}$ for four hours using the same heating and cooling schedule above. Geometric and Archimedes density measurements were performed on sintered pellets. Surface and bulk compositions of the sintered pellets were determined by XRD.

\subsection{Results and Discussion}

\subsubsection{XRD Analysis}

Surface and bulk phase assemblages were determined by XRD. Table 3.4 provides a summary of the phases observed by XRD at the various sintering temperatures and times. In general, for the baseline composition, there was very little difference in bulk compositions at all sintering temperatures and sintering soak times. Pyrochlore, brannerite, and rutile phases were detected in the bulk at similar relative peak height intensities for all pellets. However, there was an indication that uraninite was present in the bulk of the pellet sintered at $1275^{\circ} \mathrm{C}$ for four hours which suggests incomplete reaction of the $\mathrm{UO}_{2}$ under these conditions. There was no indication of uraninite at $1275^{\circ} \mathrm{C}$ for six hours.

Pyrochlore, brannerite, and rutile phases were also observed in the surface analysis. However, the relative peak height intensities for brannerite were much lower on the surface compared to the bulk. This is consistent with observations by Jurgensen and Missimer in other studies (Ref 8). Uraninite and $\mathrm{UO}_{2}$ were observed on the surface of the pellet sintered at $1275^{\circ} \mathrm{C}$ for four hours consistent with the bulk analysis. Indications of zirconolite were observed on the pellet surface sintered at $1350^{\circ} \mathrm{C}$ for four hours and indications of zirconolite and perovskite were also observed on one pellet surface sintered at $1375^{\circ} \mathrm{C}$ for two hours. These phases may be due to interactions of the surfaces with kiln furniture. Candidate kiln furniture interaction studies are continuing and will be reported separately.

XRD analysis of the $\mathrm{B} 3-13$ and $\mathrm{B} 3-17$ pellets sintered at $1350^{\circ} \mathrm{C}$ and $1375^{\circ} \mathrm{C}$ for four hours indicated zirconolite in addition to pyrochlore, brannerite, and rutile. The B3-13 and B3-17 pellets sintered at $1350^{\circ} \mathrm{C}$ for four hours had a shiny appearance which is indicative of partial melting. These pellets also stuck to the kiln furniture. This is consistent with impurity studies performed with $\mathrm{Hf} / \mathrm{Ce} / \mathrm{U}, \mathrm{Hf} / \mathrm{Ce} / \mathrm{Ce}$, and $\mathrm{Hf} / \mathrm{Pu} / \mathrm{U}$ full-size pucks at LLNL (Ref 9). The shiny appearance was not observed in pellets sintered at $1300^{\circ} \mathrm{C}$ for four hours and very little or no sticking was observed with the kiln furniture. This is also consistent with lower sintering temperature studies performed at LLNL with $\mathrm{Hf} / \mathrm{Ce} / \mathrm{U}$ and $\mathrm{Hf} / \mathrm{Ce} / \mathrm{Ce}$ (Ref 9). Again, candidate kiln furniture interaction studies are continuing and will be reported separately.

\subsubsection{Density Measurements}

Table 3.5 shows a summary of the density measurements performed on the baseline and impurity composition pellets. Pellets produced in the early stages of these studies exhibited delamination cracks, which were attributed to the condition of the die set used (i.e. possible binding or increased friction between the punch and die wall). Archimedes density measurements were not performed on these pellets. A new Carver, Inc. 1/2" diameter die which provides automatic release of trapped air was used for the remainder of the study and to repeat selected conditions. Delamination cracking has not been observed in pellets produced from the new die. Archimedes density measurements were performed on pellets produced from this new die. For comparison purposes with the current baseline sintering schedule, the total process time for each sintering temperature and soak time was calculated based on the following schedule: 1) heating to $300^{\circ} \mathrm{C}$ at $3^{\circ} \mathrm{C} / \mathrm{min}$, 2) holding at $300^{\circ} \mathrm{C}$ for 2 hours, 3) heating to the specified sintering temperature at $\left.5^{\circ} \mathrm{C} / \mathrm{min}, 4\right)$ holding at the sintering temperature for the specified time, and then 5) cooling to room temperature at $5^{\circ} \mathrm{C} / \mathrm{min}$. Percent theoretical density for the baseline composition was calculated using $\rho_{\mathrm{Th}}=5.98 \mathrm{~g} / \mathrm{cc}$. Percent shrinkage was calculated based on the decrease in pellet diameter from the nominal $1 / 2$ " die diameter. 
Table 3.4

XRD Analysis of Sintered Pellets $(\mathrm{Pu}, \mathrm{U})$

\section{Sintering}

Conditions

Temp. Time Surface Composition

\section{BASELINE COMPOSITION}

$1275^{\circ} \mathrm{C} \quad 4 \mathrm{~h}$ Pyrochlore, Brannerite, Rutile, Uraninite, $\mathrm{UO}_{2}$

$1275^{\circ} \mathrm{C} \quad 6 \mathrm{~h}$ Pyrochlore, Brannerite, Rutile

$1300^{\circ} \mathrm{C} \quad 4 \mathrm{~h} \quad$ Pyrochlore, Brannerite, Rutile

$1300^{\circ} \mathrm{C} \quad 6 \mathrm{~h}$ Pyrochlore, Rutile

$1325^{\circ} \mathrm{C} \quad 4 \mathrm{~h} \quad$ Pyrochlore, Brannerite, Rutile

$1350^{\circ} \mathrm{C} \quad 2 \mathrm{~h}$ Pyrochlore, Brannerite, Rutile*

$1350^{\circ} \mathrm{C} \quad 4 \mathrm{~h} \quad$ Pyrochlore, Rutile

$1375^{\circ} \mathrm{C} \quad 2 \mathrm{~h} \quad$ Pyrochlore, Brannerite, Rutile**

\section{B3-13 COMPOSITION}

$1300^{\circ} \mathrm{C} \quad 4 \mathrm{~h} \quad$ Pyrochlore, Brannerite, Rutile, Zirconolite

$1350^{\circ} \mathrm{C} \quad 4 \mathrm{~h}$ Pyrochlore, Brannerite, Rutile, Zirconolite

\section{B3-17 COMPOSITION}

$1300^{\circ} \mathrm{C} \quad 4 \mathrm{~h}$ Pyrochlore, Brannerite, Rutile, Zirconolite $1350^{\circ} \mathrm{C} \quad 4 \mathrm{~h}$ Pyrochlore, Brannerite, Zirconolite
Bulk Composition

Pyrochlore, Brannerite, Rutile, Uraninite

Pyrochlore, Brannerite, Rutile

Pyrochlore, Brannerite, Rutile

Pyrochlore, Brannerite, Rutile

Pyrochlore, Brannerite, Rutile

Pyrochlore, Brannerite, Rutile

Pyrochlore, Brannerite, Rutile

Pyrochlore, Brannerite, Rutile

Pyrochlore, Brannerite, Rutile, Zirconolite

Pyrochlore, Brannerite, Rutile, Zirconolite

Pyrochlore, Brannerite, Rutile, Zirconolite

Pyrochlore, Brannerite, Rutile, Zirconolite

* possible presence of zirconolite on pellet surface which may be due to interaction with kiln furniture

** perovskite was observed on one pellet surface which may be due to interaction with kiln furniture

Table 3.5

Density Measurements for Pu Sintering Study

\begin{tabular}{|c|c|c|c|c|c|c|}
\hline \multirow{2}{*}{$\begin{array}{l}\text { Total } \\
\text { Process } \\
\text { Time* }\end{array}$} & \multirow{2}{*}{$\begin{array}{c}\text { Sintering } \\
\text { Temp. }\end{array}$} & \multirow{2}{*}{$\begin{array}{l}\text { Sintering } \\
\text { Time }\end{array}$} & \multirow{2}{*}{$\begin{array}{c}\text { Percent } \\
\text { Shrinkage }\end{array}$} & \multicolumn{2}{|c|}{$\begin{array}{l}\text { Geometric Density } \\
\text { Measurements, g/cc (\% theo.) } \\
\text { pellets compacted with: }\end{array}$} & \multirow{2}{*}{$\begin{array}{c}\text { Archimedes Density } \\
\text { Measurements, g/cc (\% theo.) } \\
\text { (pellets compacted } \\
\text { with new die) } \\
\text { Bulk } \rho\end{array}$} \\
\hline & & & & Old Die & New Die & \\
\hline \multicolumn{7}{|c|}{ BASELINE COMPOSITION } \\
\hline $14.9 \mathrm{~h}$ & $1275^{\circ} \mathrm{C}$ & $4 \mathrm{~h}$ & $21 \%$ & NR & $4.92(82 \%)$ & $5.02(84 \%)$ \\
\hline $16.9 \mathrm{~h}$ & $1275^{\circ} \mathrm{C}$ & $6 \mathrm{~h}$ & $21 \%$ & $4.72(79 \%)$ & NR & \\
\hline $15.1 \mathrm{~h}$ & $1300^{\circ} \mathrm{C}$ & $4 \mathrm{~h}$ & $24 \%$ & $5.05(84 \%)$ & NR & \\
\hline $17.1 \mathrm{~h}$ & $1300^{\circ} \mathrm{C}$ & $6 \mathrm{~h}$ & $23 \%$ & $4.98(83 \%)$ & NR & \\
\hline $15.3 \mathrm{~h}$ & $1325^{\circ} \mathrm{C}$ & $4 \mathrm{~h}$ & $23 \%$ & $4.99(83 \%)$ & NR & \\
\hline $13.4 \mathrm{~h}$ & $1350^{\circ} \mathrm{C}$ & $2 \mathrm{~h}$ & $22 \%$ & NR & $5.13(86 \%)$ & $5.28(88 \%)$ \\
\hline $15.4 \mathrm{~h}$ & $1350^{\circ} \mathrm{C}$ & $4 \mathrm{~h}$ & $24 \%$ & $5.11(85 \%)$ & $5.29(88 \%)$ & $5.45(91 \%)$ \\
\hline $13.6 \mathrm{~h}$ & $1375^{\circ} \mathrm{C}$ & $2 \mathrm{~h}$ & $25 \%$ & $5.86(98 \%)$ & $5.46(91 \%)$ & $5.39(90 \%)$ \\
\hline \multicolumn{7}{|c|}{ B3-13 IMPURITY COMPOSITION } \\
\hline $15.1 \mathrm{~h}$ & $1300^{\circ} \mathrm{C}$ & $4 \mathrm{~h}$ & $21 \%$ & NR & 5.08 & 5.24 \\
\hline $15.4 \mathrm{~h}$ & $1350^{\circ} \mathrm{C}$ & $4 \mathrm{~h}$ & $21 \%$ & NR & 5.07 & 5.16 \\
\hline \multicolumn{7}{|c|}{ B3-17 IMPURITY COMPOSITION } \\
\hline $15.1 \mathrm{~h}$ & $1300^{\circ} \mathrm{C}$ & $4 \mathrm{~h}$ & $21 \%$ & NR & 4.95 & 4.96 \\
\hline $15.4 \mathrm{~h}$ & $1350^{\circ} \mathrm{C}$ & $4 \mathrm{~h}$ & $21 \%$ & NR & 4.51 & 4.84 \\
\hline
\end{tabular}

*Total process time based on $3^{\circ} \mathrm{C} / \mathrm{min}$ to $300^{\circ} \mathrm{C}$, hold 2 hours, $5^{\circ} \mathrm{C} / \mathrm{min}$ to sintering temp., hold, $5^{\circ} \mathrm{C} / \mathrm{min}$ cool $\mathrm{NR}=$ Not run 
Visual observation of all baseline composition pellets produced from the new die exhibited good quality, showed very little cracking, and exhibited very good mechanical stability upon handling. As shown in Table 3.5, a general increase in measured density was observed with an increase in sintering temperature and time. The lowest bulk density measured by the Archimedes method was $84 \%$ theoretical from a pellet sintered at the lowest temperature of $1275^{\circ} \mathrm{C}$ for four hours. The pellet sintered at $1350^{\circ} \mathrm{C}$ for four hours had a $91 \%$ theoretical density measured by the Archimedes method. The percent shrinkage of pellets ranged from $21-25 \%$. This range is consistent with full-scale pucks with Ce substituted for Pu sintered under similar conditions $(\operatorname{Ref} 9,10)$.

Acceptance criteria for the final immobilized plutonium pucks have not been determined. Leach testing of baseline and impurity pellets with similar densities $(>5.0 \mathrm{~g} / \mathrm{cc}$ ) compared to the current study have very low leach rates when subjected to MCC-1 and Product Consistency Testing (Ref 11, 12). Therefore, acceptance criteria may likely be based on composition requirements, dimensional requirements for the puck to fit in the can for the can-in-canister design, and adequate mechanical stability during puck handling operations. In addition, there should be little interaction of the pucks with the kiln furniture to minimize secondary phase formation and to allow easy removal of the pucks using remote handling capabilities. Better definition of plausible impurity compositions and performance of sintering studies with impurities are continuing in conjunction with kiln furniture interaction studies to determine optimum sintering temperatures. The upper-bound sintering temperature will most likely be based on minimizing melting of impurity compositions and optimizing kiln furniture performance.

\subsection{Conclusions}

The following conclusions can be made based on the current plutonium sintering studies:

1) Sintering temperatures ranging from $1275^{\circ} \mathrm{C}$ to $1375^{\circ} \mathrm{C}$ in air produce the proper phase assemblages from baseline A-0 composition powders. However, a longer sintering time at the lower temperature of $1275^{\circ} \mathrm{C}$ is required to achieve complete incorporation of $\mathrm{UO}_{2}$ into the proper phases.

2) Densities of the baseline compositions ranged from $82 \%$ theoretical at the low-end sintering temperature of $1275^{\circ} \mathrm{C}$ to approximately $91 \%$ theoretical in the $1350-1375^{\circ} \mathrm{C}$ range.

3) Dimensional shrinkage of pellets produced from wet ball-milled powder ranged from $21-25 \%$ over the range of sintering temperatures of $1275-1375^{\circ} \mathrm{C}$ for baseline and impurity compositions. This range is consistent with full-size puck testing with Ce substituted for $\mathrm{Pu}$.

4) Initial studies with B3-13 and B3-17 impurity compositions indicate that macroscopic partial melting observed occurs at a sintering temperature of $1350^{\circ} \mathrm{C}$ for $4 \mathrm{~h}$. The macroscopic melting was not observed in pellets sintered at $1300^{\circ} \mathrm{C}$ for $4 \mathrm{~h}$. The dimensional shrinkage of the impurity compositions was approximately $21 \%$. The $1350^{\circ} \mathrm{C}$ results are consistent with studies performed on full-size puck testing at the LLNL Pu facility and provides the first, consistent tie-in with the full-scale $\mathrm{Pu}$ puck testing.

5) The limiting maximum sintering temperature for impurity compositions will most likely be based on minimizing the flow of a low viscosity glass phase from the matrix.

\subsection{Future Work}

1) Plutonium sintering and kiln furniture interaction studies are continuing and will be reported later.

2) Plutonium impurity composition sintering studies will continue. The upper-bound sintering temperature will most likely be based on minimizing melting of impurity compositions and minimizing kiln furniture interactions. Microstructural analysis will likely be performed on selected samples as part of this evaluation.

3) Full-size plutonium studies at the LLNL Pu Facility will be required to validate the small-scale plutonium testing once the powder processing operations are finalized and the binder burnout schedule is defined.

4) Full-scale furnace testing at the CETL with maximum loads (pucks and kiln furniture) will be performed in conjunction with these studies to determine furnace temperature distribution during heat up, temperature soaks, and cool down. This information is required to ensure that all pucks in a full load can meet the temperature requirements. 


\subsection{PHASE DEVELOPMENT STUDIES}

\subsection{Experimental Procedure}

Several experimental techniques were used in this study. Initially, DTA and TGA were used to pinpoint potential reaction temperatures. From these results, samples were subjected to isothermal heat treatments at temperatures before and after detected reactions deduced from the DTA/TGA results. These samples were then analyzed using $\mathrm{x}$ ray diffraction to determine the phase assemblage. Following this initial testing, more refined analyses were made on selected individual batch components and the baseline composition using high temperature $\mathrm{x}$-ray diffraction and thermal analysis techniques.

In all testing, cerium oxide was substituted on a molar basis for the actinide oxides in the baseline formulation. Although the use of cerium as a surrogate greatly facilitates testing, the tendency of cerium to change oxidation states complicates phase development. When cerium is used in the baseline formulation, the perovskite concentration is enriched while the brannerite concentration is nonexistent. It is anticipated that much of this work will be repeated in the near future using the actinide bearing composition.

\subsubsection{Initial Thermal Analysis and Isothermal Heat Treatments}

The precursors listed in Table 2.1 along with $\mathrm{CeO}_{2}$ as a surrogate for $\mathrm{PuO}_{2}$ and $\mathrm{UO}_{2}$ on a one to one molar basis were weighed to form a $100 \mathrm{~g}$ batch. The batch was added to a polyethylene bottle filled approximately half full with $1 / 8$ inch spherical zirconia grinding media. Deionized water was added to just cover the batch and grinding media. No binders were added to the mixture. The mixture was then ball milled for 22 hours. The milled slurry was poured through a $\# 20$ sieve opening to catch the grinding media and allow the slurry to collect in a drying pan. The solution was dried for $48 \mathrm{~h}$ at $105^{\circ} \mathrm{C}$. The dried material was removed from the pan and stored for later testing. In the preliminary, baseline production process, the precursors will be calcined at $750^{\circ} \mathrm{C}$. Calcination of the precursors was not used in this study. However, some amount of $\mathrm{Ca}(\mathrm{OH})_{2}$ and $\mathrm{CaCO}_{3}$ has been shown to form during storage after calcination. Therefore, the results of this study are expected to be similar between calcined and noncalcined powders.

Differential thermal analysis and TGA were run (in duplicate) on samples of the batch to identify reaction temperatures. Typical scan rates of $10^{\circ} \mathrm{C} / \mathrm{min}$ were used in all of the testing. The DTA scans were run to the nominal sintering temperature of $1350^{\circ} \mathrm{C}$. Due to instrument limitations the TGA scans were run to $1200^{\circ} \mathrm{C}$. No weight loss was detected in the powders beyond about $750^{\circ} \mathrm{C}$. However, weight losses in pressed pucks have been observed higher than $750^{\circ} \mathrm{C}$ as discussed in section 5.0 Binder Burnout Testing. The results were also evaluated using the first derivative to aid in the identification of reactions. Once potential reaction temperatures were determined, a series of isothermal heat treatments at temperatures slightly above those depicted in the thermal analysis scans were run on the material. Approximately $10 \mathrm{~g}$ of material was heated in an alumina crucible for four hours at the selected temperature and then air quenched to room temperature. The heat treated samples were carefully divided to remove any material that may have interacted with the crucible. X-ray diffraction was run on all heat treated samples to determine the phases present.

\subsubsection{High Temperature X-ray Diffraction}

The objectives of the high temperature x-ray diffraction studies were to analyze reactions "in-situ" to better quantify reaction temperatures and to gain insight into the reaction kinetics. The baseline ceramic composition and a few individual batch components were tested. As will be discussed later, reactions upon heating involving $\mathrm{Ca}(\mathrm{OH})_{2}$ and $\mathrm{CaCO}_{3}$ were of particular interest so reagent grade chemicals of these compounds were also tested individually.

In the high temperature $\mathrm{XRD}$ experiments, a small amount of material was placed on a platinum ribbon and placed in the diffractometer. The ribbon was rapidly heated to the desired temperature and held at that temperature for times up to several hours. The detector on the diffractometer was set to an angle corresponding to a distinct diffraction peak for the tested material and the intensity of the peak was recorded as a function of time. 


\subsection{Results and Discussion}

The initial DTA and TGA scans revealed potential endothermic reactions or "trends" in the following estimated ranges: $40-150^{\circ} \mathrm{C} ; 325-370^{\circ} \mathrm{C} ; 385-475^{\circ} \mathrm{C} ; 540-725^{\circ} \mathrm{C} ; 945-990^{\circ} \mathrm{C}$; and $1230-1350^{\circ} \mathrm{C}$. It should be noted that the last endothermic trend was not "completed" at $1350^{\circ} \mathrm{C}$. Several weight changes were observed to correspond with these reaction temperatures. Weight losses were seen in the following temperature ranges: $90-120^{\circ} \mathrm{C}(0.2 \mathrm{wt} \%)$; $240-275^{\circ} \mathrm{C}(0.2 \mathrm{wt} \%) ; 300-400^{\circ} \mathrm{C}(2 \mathrm{wt} \%) ; 520-680^{\circ} \mathrm{C}(1.6 \mathrm{wt} \%)$. A small weight gain $(0.2 \mathrm{wt} \%)$ was also observed between 400 and $520^{\circ} \mathrm{C}$.

Based on these results, isothermal heat treatments were conducted on samples at $375,400,550,600,700,950$ and $1130^{\circ} \mathrm{C}$. The phase assemblage of the heat treated samples were then determined by XRD in an attempt to quantify the reaction mechanisms occurring in the various temperature regions. The XRD results are summarized in Table 4.1.

Table 4.1

Phase Assemblages of Isothermally Heated Samples

\begin{tabular}{cl}
\hline Temperature $\left({ }^{\circ} \mathrm{C}\right)$ & Phases Present/Relative Concentration Trend \\
\hline As-received & $\mathrm{TiO}_{2}$ (anatase), $\mathrm{HfO}_{2}, \mathrm{Gd}_{2} \mathrm{O}_{3}, \mathrm{CeO}, \mathrm{Ca}(\mathrm{OH})_{2}, \mathrm{CaCO}_{3}$ \\
375 & $\mathrm{TiO}_{2}$ (anatase), $\mathrm{HfO}_{2}, \mathrm{Gd}_{2} \mathrm{O}_{3}, \mathrm{CeO}, \mathrm{Ca}(\mathrm{OH})_{2} \downarrow, \mathrm{CaCO}_{3} \uparrow$ \\
400 & $\mathrm{TiO}_{2}$ (anatase), $\mathrm{HfO}_{2}, \mathrm{Gd}_{2} \mathrm{O}_{3}, \mathrm{CeO}_{2}, \mathrm{Ca}(\mathrm{OH})_{2} \downarrow, \mathrm{CaCO}_{3} \uparrow$ \\
550 & $\mathrm{TiO}_{2}$ (anatase), $\mathrm{HfO}_{2}, \mathrm{Gd}_{2} \mathrm{O}_{3}, \mathrm{CeO}_{2}, \mathrm{CaCO} \uparrow$ \\
600 & $\mathrm{TiO}_{2}$ (anatase), $\mathrm{HfO}_{2}, \mathrm{Gd}_{2} \mathrm{O}_{3}, \mathrm{CeO}_{2}, \mathrm{CaCO}_{3} \downarrow$ \\
700 & $\mathrm{TiO}_{2}$ (anatase); $\mathrm{HfO}_{2}, \mathrm{Gd}_{2} \mathrm{O}_{3}, \mathrm{CeO}_{2}$ \\
950 & $\mathrm{TiO}_{2}$ (anatase), $\mathrm{TiO}_{2}$ (rutile) $\mathrm{HfO}_{2}, \mathrm{Gd}_{2} \mathrm{O}_{3}, \mathrm{CeO}_{2}$, perovskite, pyrochlore \\
1130 & pyrochlore, perovskite, zirconolite, $\mathrm{TiO}_{2}$ (rutile), Gd $\mathrm{O}_{3}, \mathrm{CeO}_{2}$ \\
$1350^{*}$ & pyrochlore, perovskite, rutile
\end{tabular}

$\downarrow$ - relative concentration appears to be decreasing compared to lower temperature

$\uparrow$ - relative concentration appears to be increasing compared to lower temperature

* - typical results seen in the surrogate baseline composition

The isothermal heat treatment studies combined with the thermal analysis results yielded several interesting observations. The XRD scan for the as-received material indicated that carbon dioxide (present in the air) reacts with the calcium hydroxide during processing and powder storage to form a calcium carbonate phase in the starting material. Upon heating, the calcium hydroxide phase began to decompose at temperatures as low as $240^{\circ} \mathrm{C}$ (TGA weight loss data) and was completely removed from the batch by $550^{\circ} \mathrm{C}$ (XRD data). From the XRD data, it was also evident that calcium carbonate "grows-in" during the initial stages of heating. This finding was further validated by the weight gain observed in the TGA scans. The decomposition reaction involving calcium carbonate began near $550^{\circ} \mathrm{C}$ and was completed by $700^{\circ} \mathrm{C}$. Immediately after the decomposition of the calcium hydroxide and calcium carbonate $\left(\sim 700^{\circ} \mathrm{C}\right)$ there was no "calcium compound" evident in the XRD scan indicating that the calcium compounds may have decomposed into very fine $\mathrm{CaO}$ crystallites. Well dispersed, small crystallites of $\mathrm{CaO}$ would not be detectable by XRD. Upon heating to $950^{\circ} \mathrm{C}$, both perovskite and pyrochlore began to form in the ceramic. Upon further heating, the pyrochlore phase became predominant.

In an effort to better understand the observations described above, additional testing using thermal analysis and high temperature XRD was performed on individual batch components and the baseline composition. Both DTA and TGA were performed on reagent grade calcium hydroxide (Figure 4.1). This testing confirmed the observed behavior of calcium hydroxide in the batch materials (i.e. decomposition of $\mathrm{Ca}(\mathrm{OH})_{2}$, in-growth of $\mathrm{CaCO}_{3}$, decomposition of $\mathrm{CaCO}_{3}$ ). 


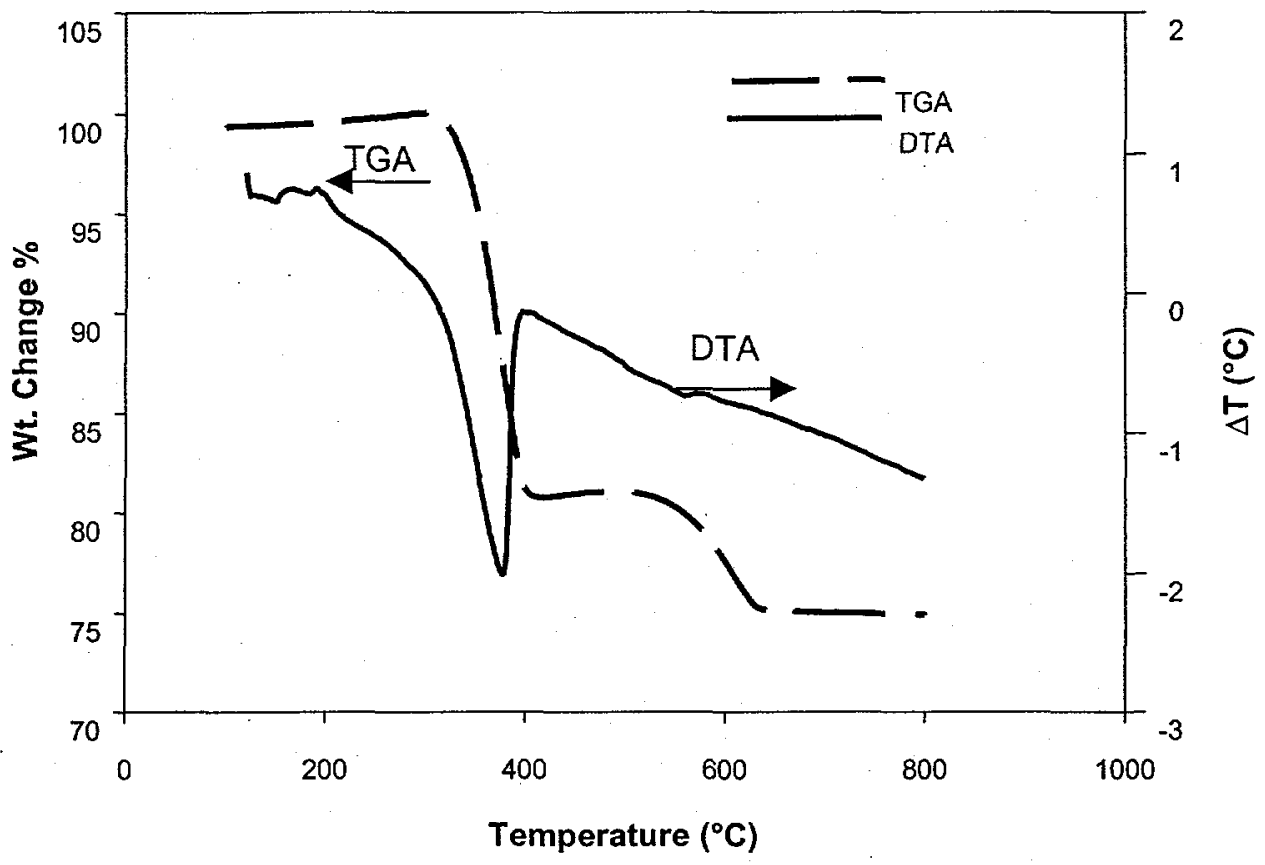

Figure 4.1 DTA and TGA of reagent grade $\mathrm{Ca}(\mathrm{OH})_{2}$ showing the decomposition of $\mathrm{Ca}(\mathrm{OH})_{2}$, in-growth of $\mathrm{CaCO}_{3}$ and decomposition of $\mathrm{CaCO}_{3}$.

High temperature XRD testing on reagent grade $\mathrm{Ca}(\mathrm{OH})_{2}$ also confirmed the behavior upon heating of calcium hydroxide in the baseline composition. Figure 4.2 shows the decrease in relative intensity of the major $\mathrm{Ca}(\mathrm{OH})_{2}$ diffraction peak as a function of time for a sample heated constantly at $400^{\circ} \mathrm{C}$.

The in-growth of calcium carbonate on $\mathrm{Ca}(\mathrm{OH})_{2}$ was observed in-situ by heating reagent grade $\mathrm{Ca}(\mathrm{OH})_{2}$ at $450^{\circ} \mathrm{C}$ and observing an increase in intensity in the major $\mathrm{CaCO}_{3}$ diffraction peak (Figure 4.3).

High temperature XRD performed on the surrogate baseline composition also provided insight into ceramic phase formation. In separate experiments, a sample of the baseline composition was rapidly heated to $1000^{\circ} \mathrm{C}$ and the formations of perovskite and pyrochlore were monitored by examining a distinct peak of the respective phase. The perovskite was observed to rapidly form in the material to an apparent saturation concentration (Figure 4.4). In contrast, the pyrochlore phase appeared to form gradually and increased in concentration with time at $1000^{\circ} \mathrm{C}$ (Figure 4.5). The differences in the observed growth of these two phases in the high temperature XRD studies combined with the isothermal heat treatment studies led to the following hypotheses. The perovskite formed initially in the ceramic and reached a saturation concentration upon further heating. The perovskite may have acted as a precursor for pyrochlore development. Once the pyrochlore phase development was. initiated the chemical driving forces in the system acted to form the predominant pyrochlore phase upon continued heating.

The formation of the pyrochlore phase was also observed to coincide with the densification of the ceramic. Dilatometry scans on baseline ball-milled material have shown that the densification of the ceramic begins at approximately $920^{\circ} \mathrm{C}$ and continues quite rapidly upon further heating (Figure 4.6). It is also interesting to note in the dilatometry curve the apparent increase in expansion from approximately 280 to $450^{\circ} \mathrm{C}$. This temperature range roughly coincides with the decomposition of $\mathrm{Ca}(\mathrm{OH})_{2}$ and in-growth of $\mathrm{CaCO}_{3}$ reactions observed in the thermal analysis and XRD studies.

The sample material tested by dilatometry was calcined at $750^{\circ} \mathrm{C}$ prior to testing. However, $\mathrm{XRD}$ results on the calcined powder showed that most of the calcium was present in the form of $\mathrm{Ca}(\mathrm{OH})_{2}$ and $\mathrm{CaCO}_{3}$ after calcination and storage. 


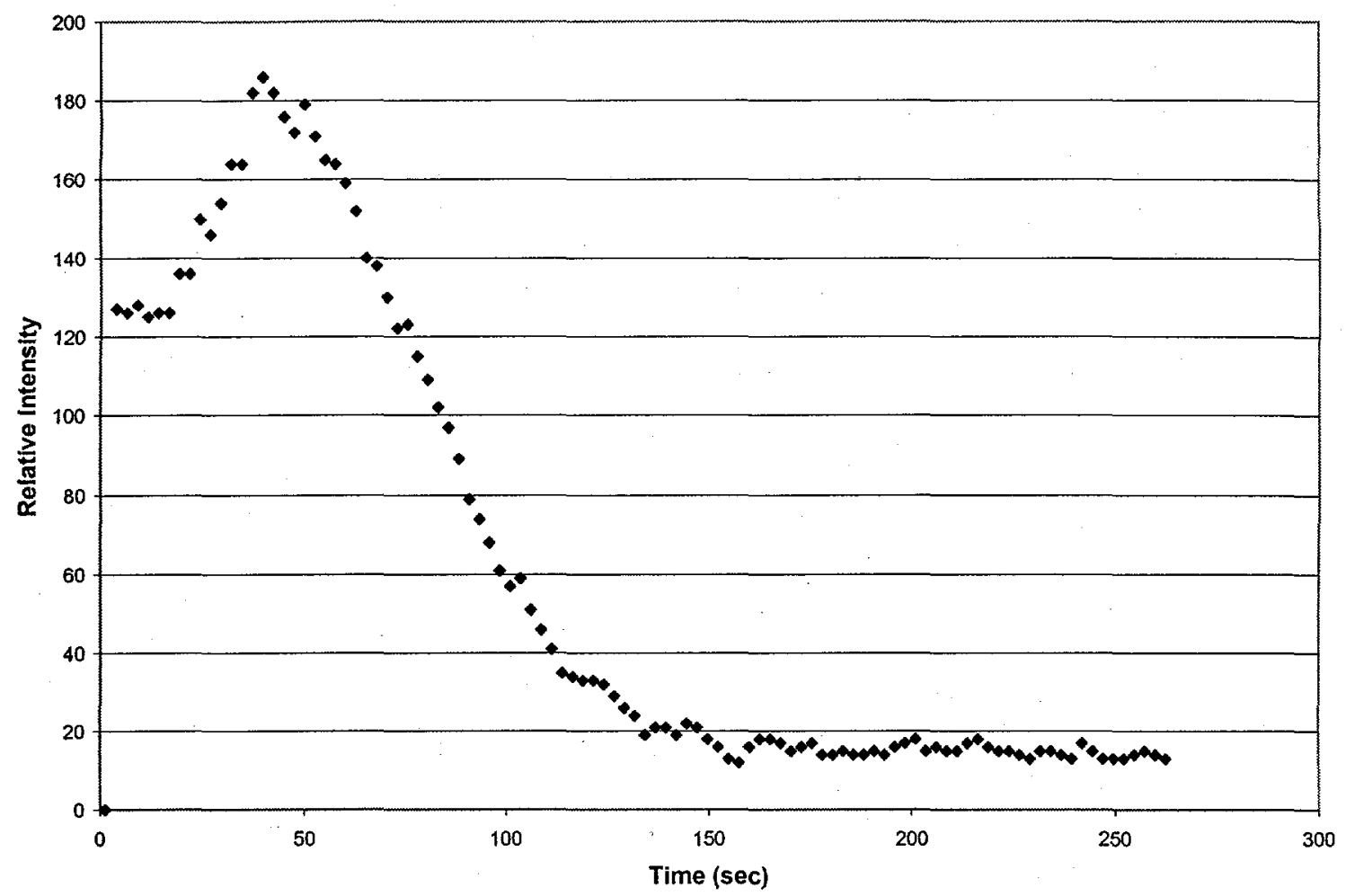

Figure 4.2. Intensity of the major $\mathrm{Ca}(\mathrm{OH})_{2}$ diffraction peak vs. time for reagent grade $\mathrm{Ca}(\mathrm{OH})_{2}$ indicating the rapid decomposition of calcium hydroxide at $400^{\circ} \mathrm{C}$.

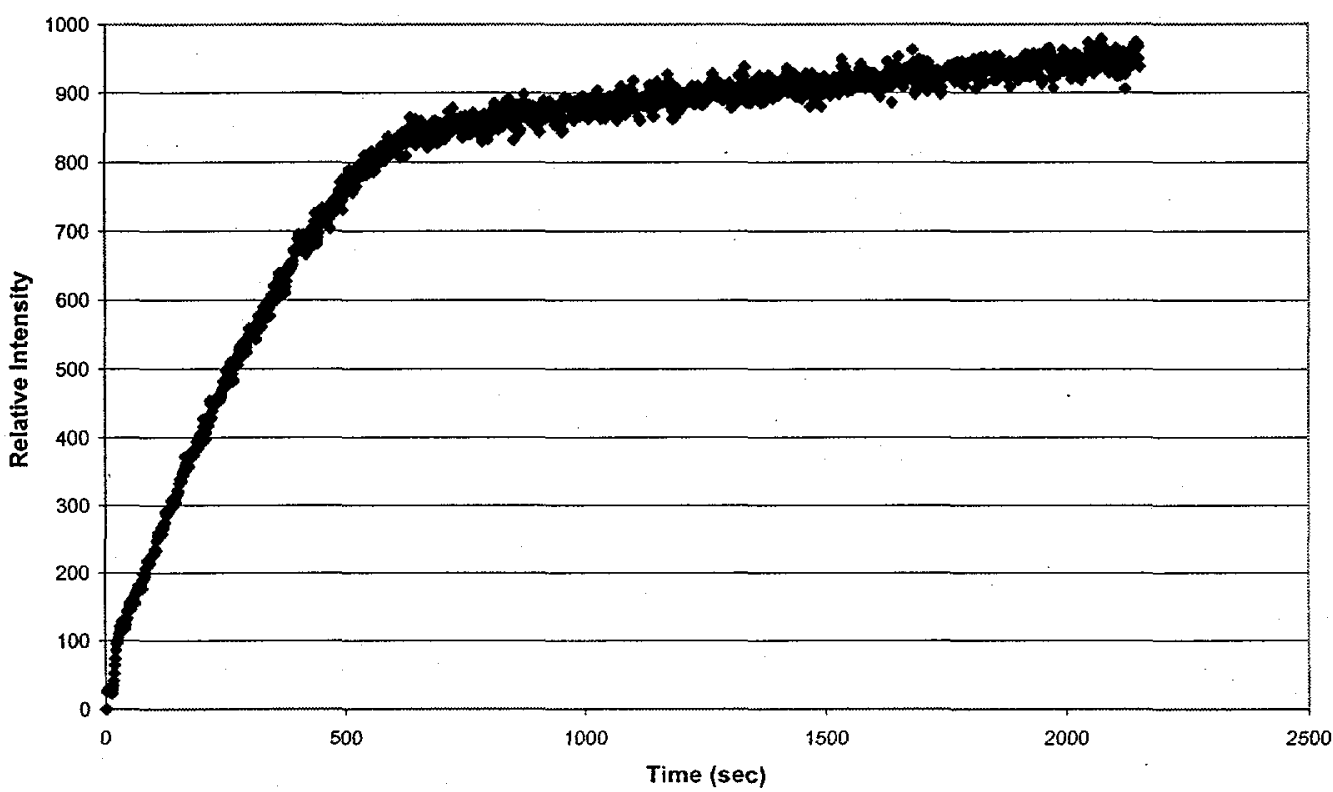

Figure 4.3. Intensity of the major $\mathrm{CaCO}_{3}$ diffraction peak vs. time for reagent grade $\mathrm{Ca}(\mathrm{OH})_{2}$ indicating the in-growth of $\mathrm{CaCO}_{3}$ at $450^{\circ} \mathrm{C}$. 


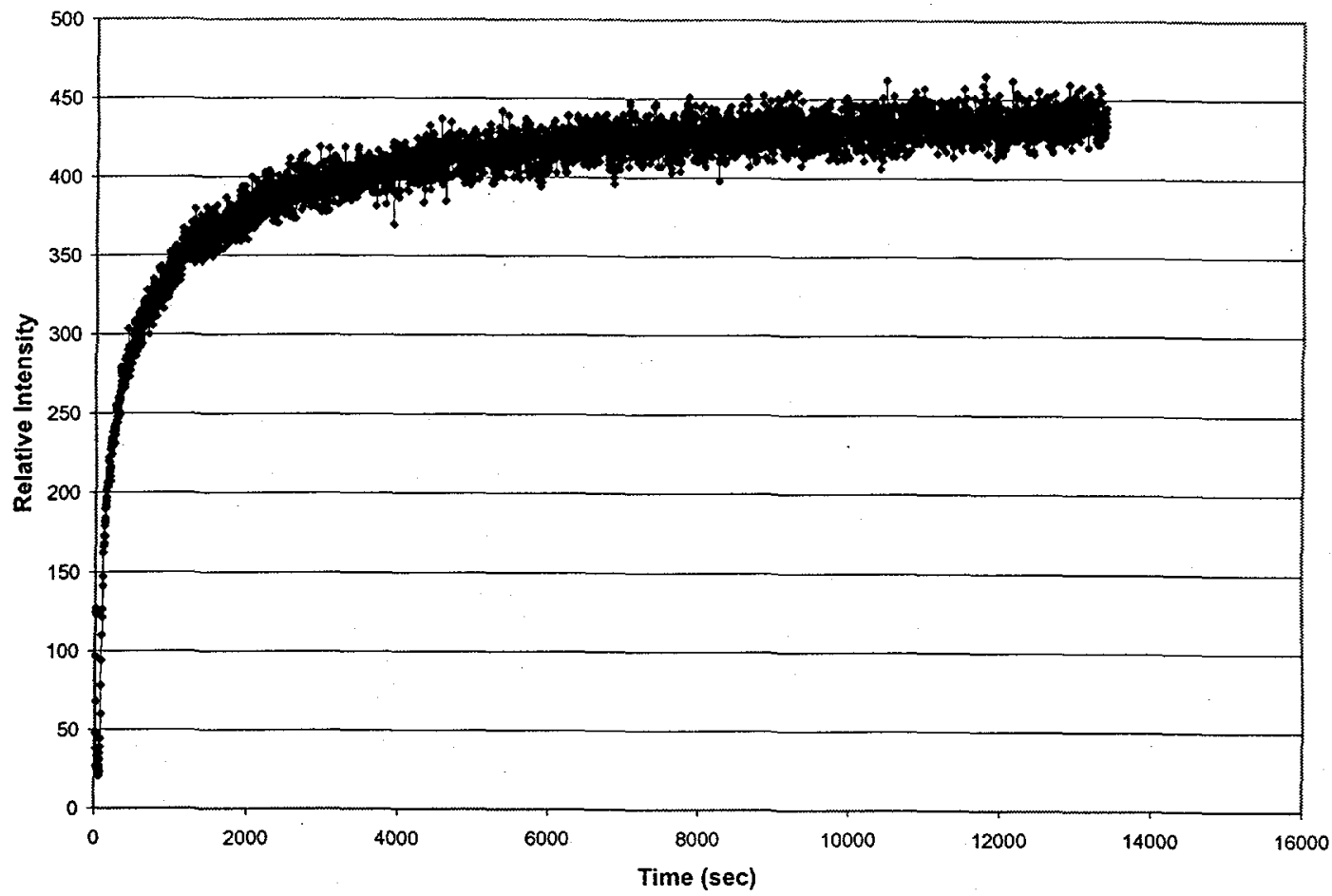

Figure 4.4. Formation of perovskite in the baseline surrogate composition at $1000^{\circ} \mathrm{C}$. Rapid in-growth occurs which quickly reaches a saturation concentration as indicated by little increase in peak intensity with increasing time.

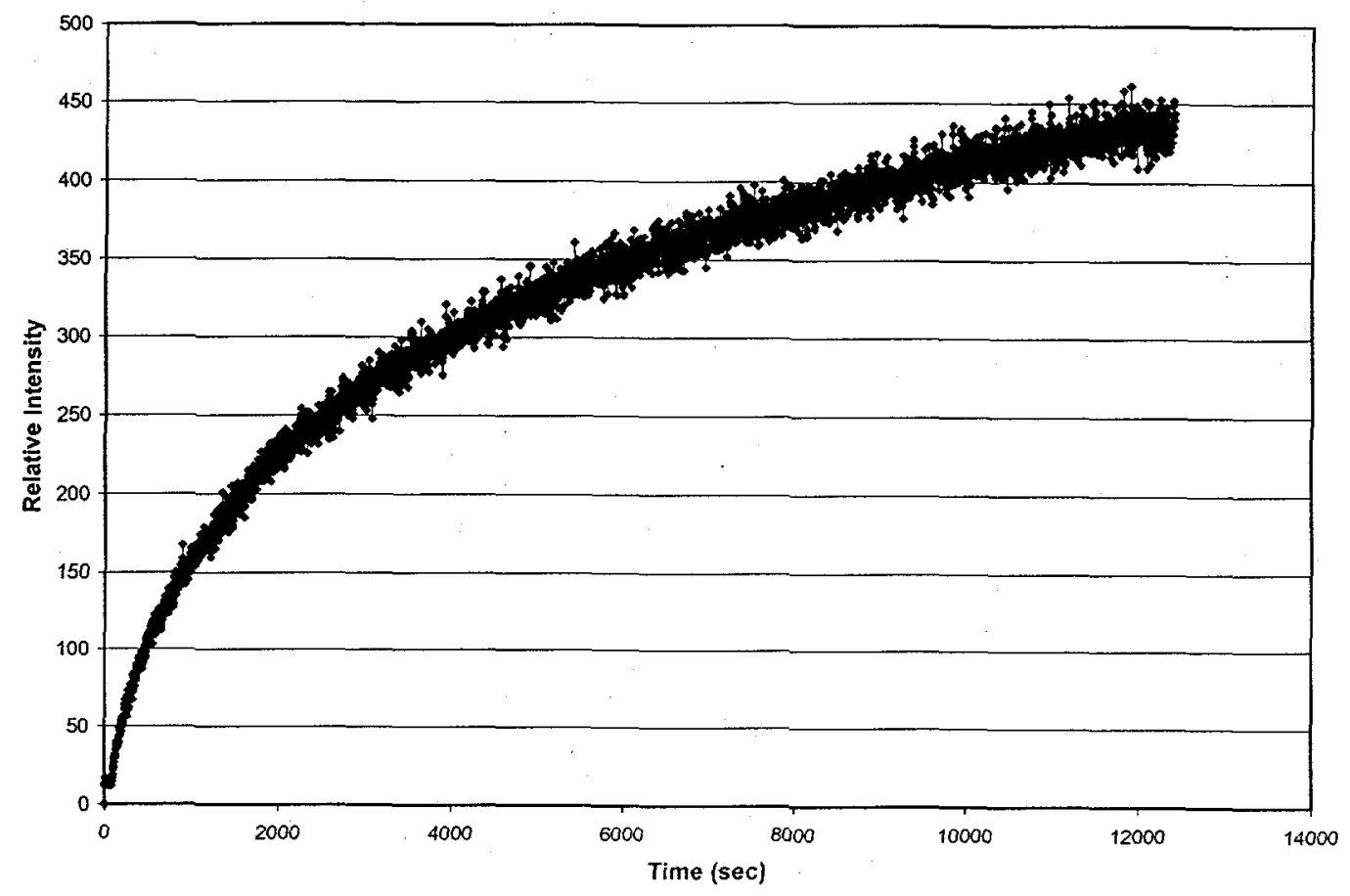

Figure 4.5. Formation of pyrochlore in the baseline surrogate composition at $1000^{\circ} \mathrm{C}$. The pyrochlore concentration increases more gradually with increasing time. 


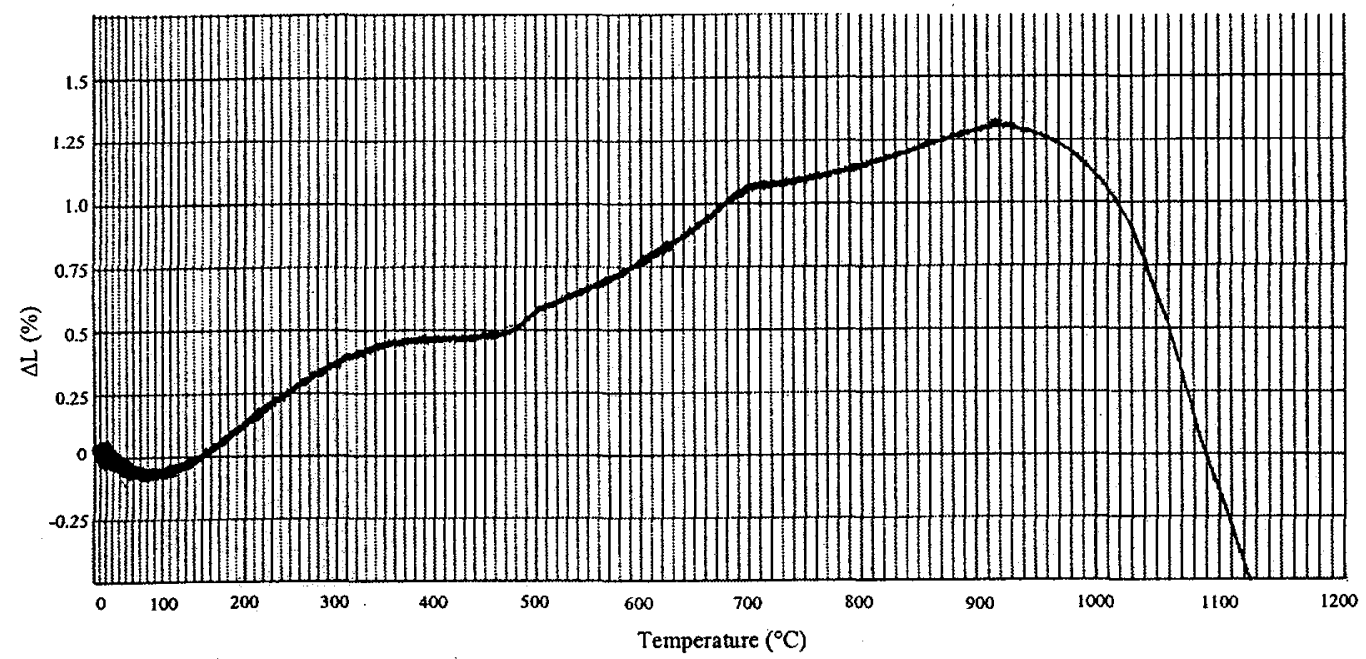

Figure 4.6. Dilatometry scan of baseline ceramic formulation. Batch was calcined at $750^{\circ} \mathrm{C}$ prior to testing.

\subsection{Conclusions}

The following conclusions were made from this study:

1) $\mathrm{Ca}(\mathrm{OH})_{2}$ is responsible for low temperature phase changes in the baseline composition

- Some $\mathrm{CaCO}_{3}$ "grew into" the batch during storage before pressing and sintering $\mathrm{Ca}(\mathrm{OH})_{2}$ began to decompose as low as $240^{\circ} \mathrm{C}$ and was removed by $550^{\circ} \mathrm{C}$

- $\mathrm{CaCO}_{3}$ in-growth occurred during and after $\mathrm{Ca}(\mathrm{OH})_{2}$ decomposition

- $\mathrm{CaCO}_{3}$ decomposition occurred between about 550 and $700^{\circ} \mathrm{C}$

- No distinct Ca phase was evident immediately following $\mathrm{Ca}(\mathrm{OH})_{2} / \mathrm{CaCO}_{3}$ decomposition

2) Upon heating to higher temperatures

- Perovskite formed quickly to a saturation concentration

- Pyrochlore formed gradually and became the predominant phase upon further heating

- Densification of the ceramic coincided with the formation of pyrochlore

\subsection{Future Work}

1) Thermal analysis on Hf-Pu-U baseline composition: TGA will be performed on the plutonium baseline composition to compare to the results obtained on the Hf-Ce-Ce surrogate baseline composition. Additionally, differential scanning calorimetry (DSC) will be used to examine low temperature reactions in the Pu baseline composition (this analysis is limited to $\sim 700^{\circ} \mathrm{C}$ ). Unfortunately, no glove box differential thermal analysis (DTA) equipment is available to examine the higher temperature regimes.

2) Isothermal heat treatments and x-ray diffraction $(X R D)$ : An isothermal heat treatment/XRD study, similar to the study completed on the Hf-Ce-Ce surrogate baseline composition, will be completed on the Pu baseline composition. The isothermal heat treatment temperatures may vary slightly from the $\mathrm{Hf}-\mathrm{Ce}-\mathrm{Ce}$ baseline study depending on the results of the thermal analysis studies described above for the $\mathrm{Pu}$ baseline composition.

3) Average impurity composition studies: At a later date, the thermal analysis testing and isothermal heat treatment/XRD testing described above may be completed on an average impurity $\mathrm{Pu}$ ceramic composition. This will be used to identify variations in reaction temperatures and intermediate phase formation due to the presence of impurities.

4) Microstructural/chemical analyses: The isothermal heat treatment and high temperature XRD studies indicated that intermediate phases may form during the sintering process. Isothermal heat treatments coupled with careful 
microstructural examination (electron microprobe and scanning electron microscopy coupled with energy dispersive spectroscopy) will be used in an attempt to identify these intermediate reactions and phases. This will be performed on both the $\mathrm{Hf}-\mathrm{Ce}-\mathrm{Ce}$ baseline composition and the Hf-Pu-U baseline composition to correlate with the aforementioned studies.

5) Perovskite phase formation: The isothermal heat treatment and high temperature $\mathrm{x}$-ray diffraction testing indicated that perovskite may be forming as a precursor to pyrochlore formation and densification. High temperature XRD studies using perovskite as the precursor calcium source will be performed on the baseline $\mathrm{Hf}-\mathrm{Ce}-\mathrm{Ce}$ composition. This testing will be contrasted to the previous high temperature XRD work performed on the baseline Hf-Ce-Ce composition to gain insight into the role of perovskite in the phase development and sintering process.

\subsection{BINDER BURNOUT TESTING}

\subsection{Experimental Procedure}

To better understand the thermal reactions occurring in the ceramic form during sintering, thermal analyses were performed on several powders and full-size pucks fabricated using different processing methods and organic additives. The analysis methods include:

1) TGA-DTA on the organic additives and processed powders containing the organic additives (SRTC/LLNL),

2) dilatometry studies during sintering (SRTC and ANSTO), and

3) binder burnout - Fourier Transform Infrared Spectroscopy (BBO-FTIR) testing using full-size pucks (LLNL).

The three test capabilities complement each other to help identify the thermal reactions occurring during binder burnout. Initial testing indicated that binder burnout behavior is different between binder only, binder mixed with powders, and pressed pucks with binder. However, TGA-DTA on powders provide valuable input to develop test matrices for the full-scale binder burnout studies and to aid in the understanding of the burnout process under prototypical conditions. The BBO-FTIR analysis ties the actual offgas to specific additives studied by TGA-DTA. The dilatometry studies provide information on stages of the heating schedule that produce expansion in the puck which can result in cracking. Finally, BBO-FTIR testing with full-scale pucks provides weight loss and FTIR offgas analysis and information about how the pucks behave during the binder burnout process. Appendix A provides a summary of the weight loss data determined in the preliminary TGA-DTA studies performed on the powders, while Appendix B is a summary of the weight loss data on some of the key BBO-FTIR tests on pucks.

Standard methods and equipment were used to perform the TGA-DTA on powders and laser dilatometry on pucks. However, commercial equipment was not available to monitor weight losses and offgas components of a full-size puck as a function of time. A large-scale binder burnout test system was developed at LLNL that allows binder burnout testing on full-scale nonradioactive pucks. An inline FTIR system was integrated with the offgas system, which provides characterization of the various species volatilizing during the heating schedule. A full-size puck is placed into a basket suspended from a scale inside the binder burnout furnace. The data collection system records the weight of the puck at one-minute intervals during the heating cycle. Furnace setpoint and process temperature data are also collected. The FTIR is used to analyze 2 to $6 \mathrm{~mL} / \mathrm{min}$ of offgas through a two meter hot gas cell. Correlation of the data provides information on the relationship of the heating cycle to specific weight loss regions and offgassing of specific components.

Temperature gradient measurements were also performed on full-size pucks at LLNL. Pucks were pressed with thermocouples contacting the puck surface and embedded in the core. Furnace setpoint and process temperature data were collected along with the puck surface and core temperatures.

To date, binder burnout testing can be categorized into the following areas:

1) evaluating the differences in burnout behavior between binders alone, powders, and pressed pucks,

2) identification of burnout temperature regions,

3) determining effect of low temperature holds on dehydration and decomposition and combustion of organic materials 
4) determination of thermal gradients on pertinent to full-size pucks during the sintering schedule,

5) determining effects of agglomeration (granulation) methods,

6) controlling offgas behavior to ensure product quality,

7) determining effects of grinding aids, and

8) determining effects of impurity compositions.

\subsection{Results and Discussion}

\subsubsection{Binder vs. Powder vs. Puck Thermal Analysis Data}

The original baseline process for plutonium ceramic fabrication studies involved wet ball milling of the powders to provide mixing followed by the addition of polyethylene glycol (PEG) as a binder to aid in granulation and in enhancing green puck strength. A baseline sintering schedule was developed from this testing:

- heat at $3^{\circ} \mathrm{C} / \mathrm{min}$ to $300^{\circ} \mathrm{C}$,

- hold for $2 \mathrm{~h}$,

- heat at $5^{\circ} \mathrm{C} / \mathrm{min}$ to $1350^{\circ} \mathrm{C}$,

- hold for $4 \mathrm{~h}$, and

- cool at $\sim 5^{\circ} \mathrm{C} / \mathrm{min}$ to $110^{\circ} \mathrm{C}$.

Thermal analysis was performed on binders only, binders mixed with powders, and pressed pucks containing binders from the baseline process. Results indicate a significant difference in binder burnout behavior between the various conditions. TGA-DTA of the PEG $8 \mathrm{~K}$ material by itself in air indicates that decomposition begins at $170^{\circ} \mathrm{C}$ and completely decomposes by $225^{\circ} \mathrm{C}$ at a steady rate. However, when the PEG is mixed (5 wt\%) with the precursor powder, several stages of weight change occur from $195^{\circ} \mathrm{C}$ up to $680^{\circ} \mathrm{C}$. A $2.7 \mathrm{wt} \%$ loss occurred as the powder was heated from $195^{\circ} \mathrm{C}$ to $300^{\circ} \mathrm{C}$. There was little weight change until approximately $425-450^{\circ} \mathrm{C}$ when approximately $0.5 \mathrm{wt} \%$ of material was lost. A small weight gain occurred from $450^{\circ} \mathrm{C}$ to $550^{\circ} \mathrm{C}$. After this, an additional $4.0 \mathrm{wt} \%$ of material was lost up to $680^{\circ} \mathrm{C}$. A comparison of the data shows a large difference in the behavior of the binder only versus the ceramic powder containing the binder. Only a small weight loss $(1.5 \%$ out of a total of $6.7 \%$ ) occurred in the powder below the $225^{\circ} \mathrm{C}$ temperature region, which is where all of the binder decomposed when heated by itself. In relation to the baseline binder burnout schedule, a significant amount of weight loss occurs prior to the hold temperature of $300^{\circ} \mathrm{C}$ and the remaining weight loss does not occur until above $550^{\circ} \mathrm{C}$.

The general trend is that the relevent offgassing temperature regions shift and the pucks continue to offgas at temperatures $>700^{\circ} \mathrm{C}$ compared to powders. A full-size puck was tested in the BBO-FTIR furnace using the baseline binder burnout schedule. The weight loss data and temperature schedule are shown in Figure 5.1. The data show that almost all of the weight loss occurs before the $300^{\circ} \mathrm{C}$ hold is reached, and very little material is lost during the hold. The data also show a brief region between 200 to $240^{\circ} \mathrm{C}$ during the first ramp where no change occurs. FTIR has confirmed that the source of weight loss changes from water to organics during this region as discussed in section 5.2.2. Additional weight loss occurs during the second ramp beginning at $\sim 450^{\circ} \mathrm{C}$. 


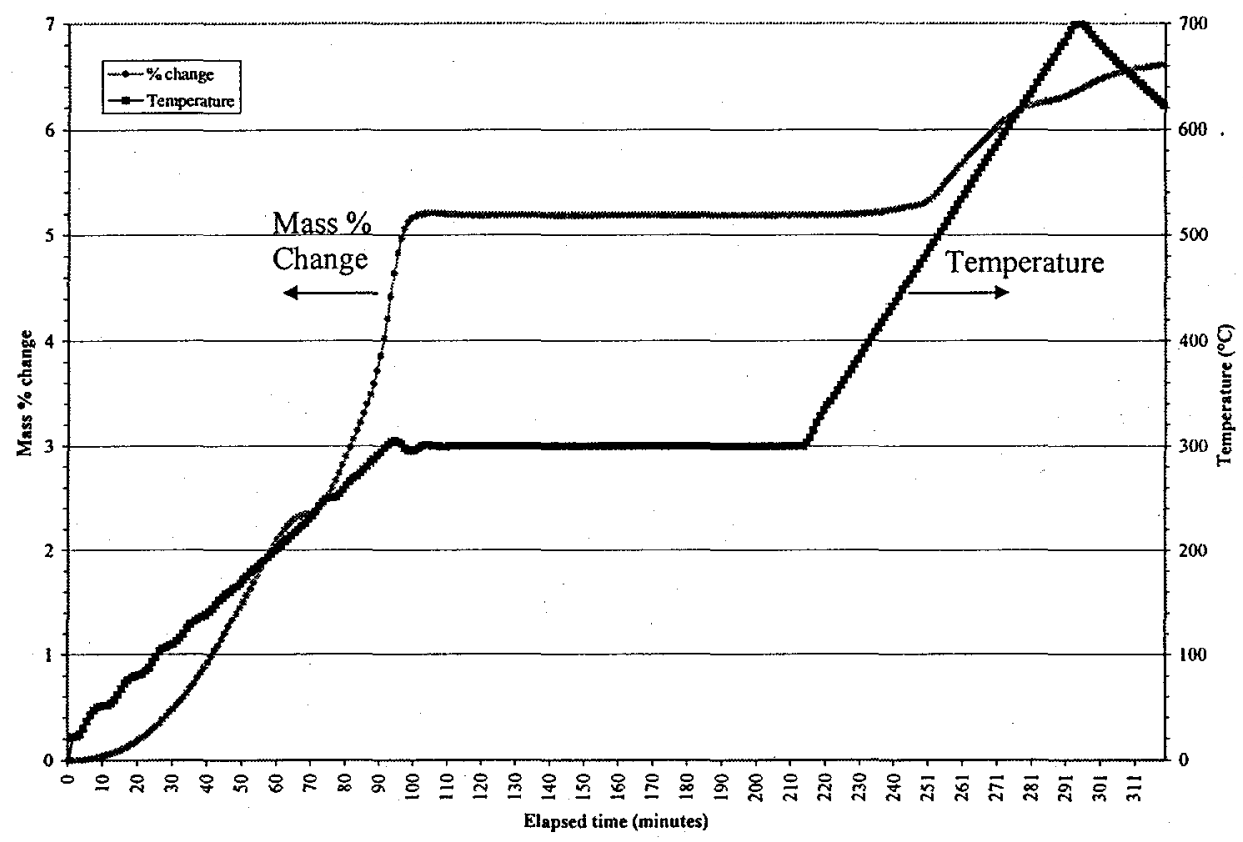

Figure 5.1. Baseline binder burnout of a full-size puck produced with wet ball milled powder containing 5 wt $\%$ PEG $8 \mathrm{~K}$ binder.

In contrast to the powder TGA-DTA data, onset of water loss occurs almost immediately in the puck. Both the powder and puck exhibit a major weight loss region below $300^{\circ} \mathrm{C}$ and one at higher temperatures. In the puck, the $<300^{\circ} \mathrm{C}$ temperature region had a greater total weight loss $(5.2 \%$ vs. $2.7 \%)$ and the second major weight loss region started at a lower temperature $\left(450^{\circ} \mathrm{C}\right.$ vs. $\left.550^{\circ} \mathrm{C}\right)$. The powder had a more even weight loss during heating and burnout was complete by $680^{\circ} \mathrm{C}$. However, the puck was still losing weight when it reached $700^{\circ} \mathrm{C}$, the temperature limit of the BBO-FTIR test. A comparison of the burnout behavior of binder only, powder + binder, and pressed powder with binder is shown in Table 5.1.

Table 5.1

Comparison of Burnout Behavior of Baseline Material

\begin{tabular}{|c|c|c|c|c|c|}
\hline \multicolumn{2}{|c|}{ PEG 8K } & \multicolumn{2}{|c|}{$\begin{array}{c}\text { TGA of } \\
\text { Baseline Powder }+5 \text { wt } \% \text { PEG }\end{array}$} & \multicolumn{2}{|c|}{$\begin{array}{l}\text { BBO-FTIR (Baseline Schedule) of } \\
\text { Baseline Puck with } 5 \text { wt\% PEG }\end{array}$} \\
\hline $\begin{array}{c}\text { Temperature } \\
\text { Range }\end{array}$ & Wt. Change & $\begin{array}{c}\text { Temperature } \\
\text { Range }\end{array}$ & Wt. Change & $\begin{array}{c}\text { Temperature } \\
\text { Range }\end{array}$ & Wt. Change \\
\hline $170-225^{\circ} \mathrm{C}$ & $-100 \%$ & $\begin{array}{l}195-300^{\circ} \mathrm{C} \\
425-450^{\circ} \mathrm{C} \\
450-550^{\circ} \mathrm{C} \\
550-680^{\circ} \mathrm{C}\end{array}$ & $\begin{array}{l}-2.7 \% \\
-0.5 \% \\
+0.5 \% \\
-4.0 \%\end{array}$ & $\begin{array}{c}\mathrm{RT}-300^{\circ} \mathrm{C} \\
450-700^{\circ} \mathrm{C} \\
>700^{\circ} \mathrm{C}\end{array}$ & $\begin{array}{c}-5.2 \% \\
-1.4 \% \\
\text { continued } \\
\text { wt. loss }\end{array}$ \\
\hline
\end{tabular}

\subsubsection{Identification of Burnout Regions}

A comparison of results for the full-size puck presented in Figure 5.1 to TGA-DTA data from ANSTO on a small piece of a full-size puck reveals some similarities. The ANSTO TGA-DTA data (Ref 13) indicates an endotherm at $70^{\circ} \mathrm{C}$, which corresponds to the onset of water loss in the full-size puck. The next weight change region in the TGA-DTA corresponded to decomposition of organics between 240 to $300^{\circ} \mathrm{C}$ and is consistent with the second onset of weight loss in the puck. The next weight loss stage in the puck is initiated around $450^{\circ} \mathrm{C}$, which is fairly consistent with the $430^{\circ} \mathrm{C}$ ANSTO loss onset. The final onset of weight loss around $600^{\circ} \mathrm{C}$ is also closely 
coordinated and attributed to $\mathrm{CO}_{2}$ outgassing. These weight loss regions are also consistent with the high temperature $\mathrm{XRD}$ data (Section 4.1.2) obtained at SRTC indicating decomposition of $\mathrm{Ca}(\mathrm{OH})_{2}$ at $400^{\circ} \mathrm{C}$ and decomposition of $\mathrm{CaCO}_{3}$ at $600^{\circ} \mathrm{C}$. The ANSTO TGA-DTA did indicate that this weight loss continued to $800^{\circ} \mathrm{C}$, which cannot currently be measured in the BBO-FTIR furnace but is known to occur because of total weight loss values for sintered pucks.

Based on the offgas results for the baseline puck, SRTC high temperature XRD data, ANSTO TGA-DTA data, and known ceramic matrix thermal reactions, principle offgassing regions for the full-size puck were defined. These regions are shown in Figure 5.2 and can be sub-divided into several steps. First is the controlled removal of water during the water boil off or dehydration step. Second is the controlled removal of organics during the decomposition and combustion step. Third is the pyrolysis step, which does not appear to be an issue for the current process. Studies have shown that the temperature range of decomposition and combustion can overlap the dehydration and pyrolysis steps. Fourth is the dehydroxylation step, where waters of hydration are released at much higher temperatures. The fifth and final step is the removal of all remaining organics and carbonate compounds as $\mathrm{CO}_{2}$ gas. Temperature control throughout these regions directly impacts the integrity of the puck. The plutonium ceramic form has similar offgas regions compared to other ceramic materials, such as clay, during the low temperature portion of the sintering cycle. For a typical fired clay material, the reactions are divided into the following regions: loss of mechanical water (dehydration) from 250 to $350^{\circ} \mathrm{C}$; oxidation of organic matter from 250 to $450^{\circ} \mathrm{C}$; dehydroxylation from 450 to $670^{\circ} \mathrm{C}$; and decomposition of carbonates from 790 to $870^{\circ} \mathrm{C}(\operatorname{Ref} 14$ ).

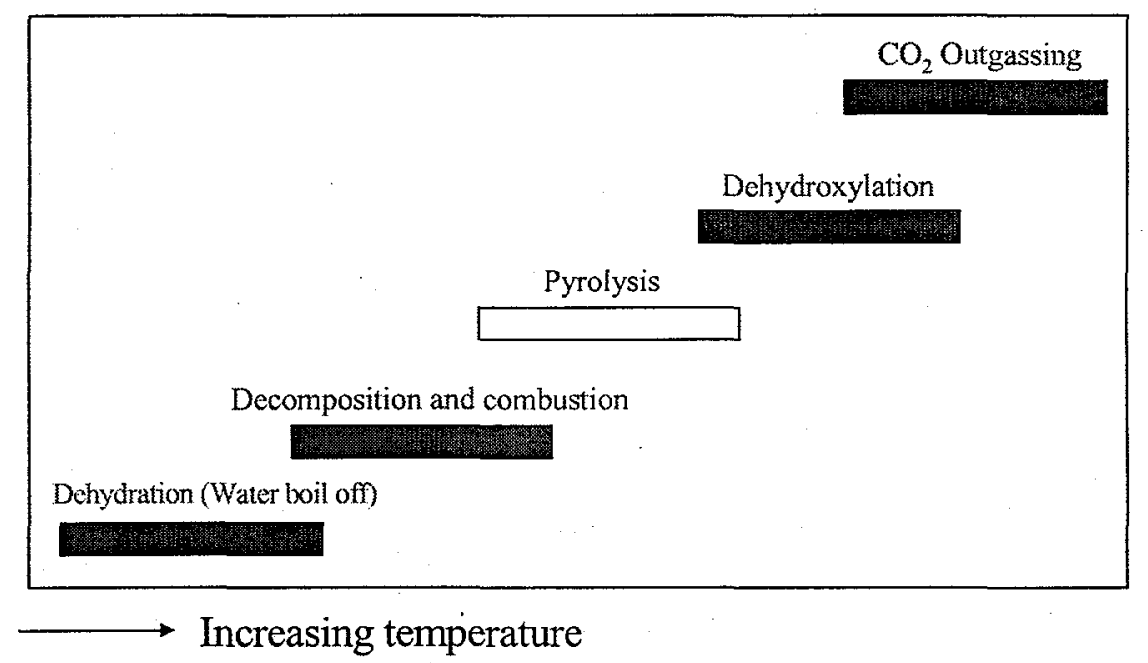

Figure 5.2. Binder burnout offgassing regions.

\subsubsection{Effect of Temperature Holds and Ramp Rates}

Since the majority of the total weight loss occurs during the binder burnout region of the sintering schedule or, more specifically, the dehydration region, several BBO-FTIR tests were performed to optimize this portion of the binder burnout cycle. Through optimization of this region, it was hypothesized that low temperature cracking seen in the Iab at LLNL and ANSTO could be eliminated. Low temperature hold tests were performed on full size pucks pressed from ball milled powders at soak temperatures ranging from 100 to $200^{\circ} \mathrm{C}$. Pucks were heated to the soak temperatures at $3^{\circ} \mathrm{C} / \mathrm{min}$ and held at the soak temperatures for $2 \mathrm{~h}$. Figure 5.3 shows the percent weight change as a function of time for these experiments.

Generally, for all of the low temperature holds, the pucks reached a plateau with respect to mass loss after approximately one hour into the various schedules. Very little or no additional weight change was observed in the hold temperatures $<180^{\circ} \mathrm{C}$ once this plateau was reached. On the other hand, the $180^{\circ} \mathrm{C}$ and $200^{\circ} \mathrm{C}$ holds showed additional weight loss further into the hold after the first plateau. Both pucks appear to be in equilibrium at the end of the hold. The mass loss values for these pucks would indicate that organic material was starting to outgas after 
the initial water was boiled off. FTIR analysis verified that the organic material was starting to outgas during the low temperature hold. By instituting a lower temperature hold, the schedule enables dehydration of the puck without initiating a large amount of organic decomposition and combustion. The low temperature hold studies were also performed with pucks pressed from material granulated in a tumble double cone granulator (GEMCO). These tests also indicated that a $180^{\circ} \mathrm{C}$ hold was optimal for removing water and maintaining puck integrity. The BBOFTIR low temperature hold tests show that water is not suddenly and completely exhausted from the puck at $100^{\circ} \mathrm{C}$. Instead, it gradually boiled off during a range of furnace temperatures up to around $180^{\circ} \mathrm{C}$. The temperature delay for dehydration is believed to be the result of heat transfer limitations. While some time is required to heat the puck surfaces, the puck interior requires longer times to boil off the water.

Slower ramp rates have also been used with the GEMCO material to improve puck integrity. By using a much slower heating rate, the offgassing regimes were slightly shifted so that they were not overlapping. In addition, the total amount of material lost up to $700^{\circ} \mathrm{C}$ increased with the slower heating rates. The slower ramp rates are believed to create a "thermal equilibrium" situation where the puck surface and core are in equilibrium with the furnace atmosphere, thereby eliminating the heat transfer limit created with a compacted powder. Using the FTIR offgas analysis in conjunction with the weight loss data for the "thermal equilibrium" schedule, temperature regions were identified where no material was offgassing or being lost. Thus, the ramp rates in these regions may be able to be increased. Limited testing has shown that higher ramp rates can be used without severely impacting puck integrity in these low or non-loss regions. It should be noted that other factors, such as the low temperature expansion of the pucks can contribute to cracking. The expansion can be affected by powder processing variables, such as, binder dispersal, granule size, and pressing pressure. Therefore, as the powder processing conditions are optimized, the proper hold temperatures and ramp rates will be defined using the BBO-FTIR.

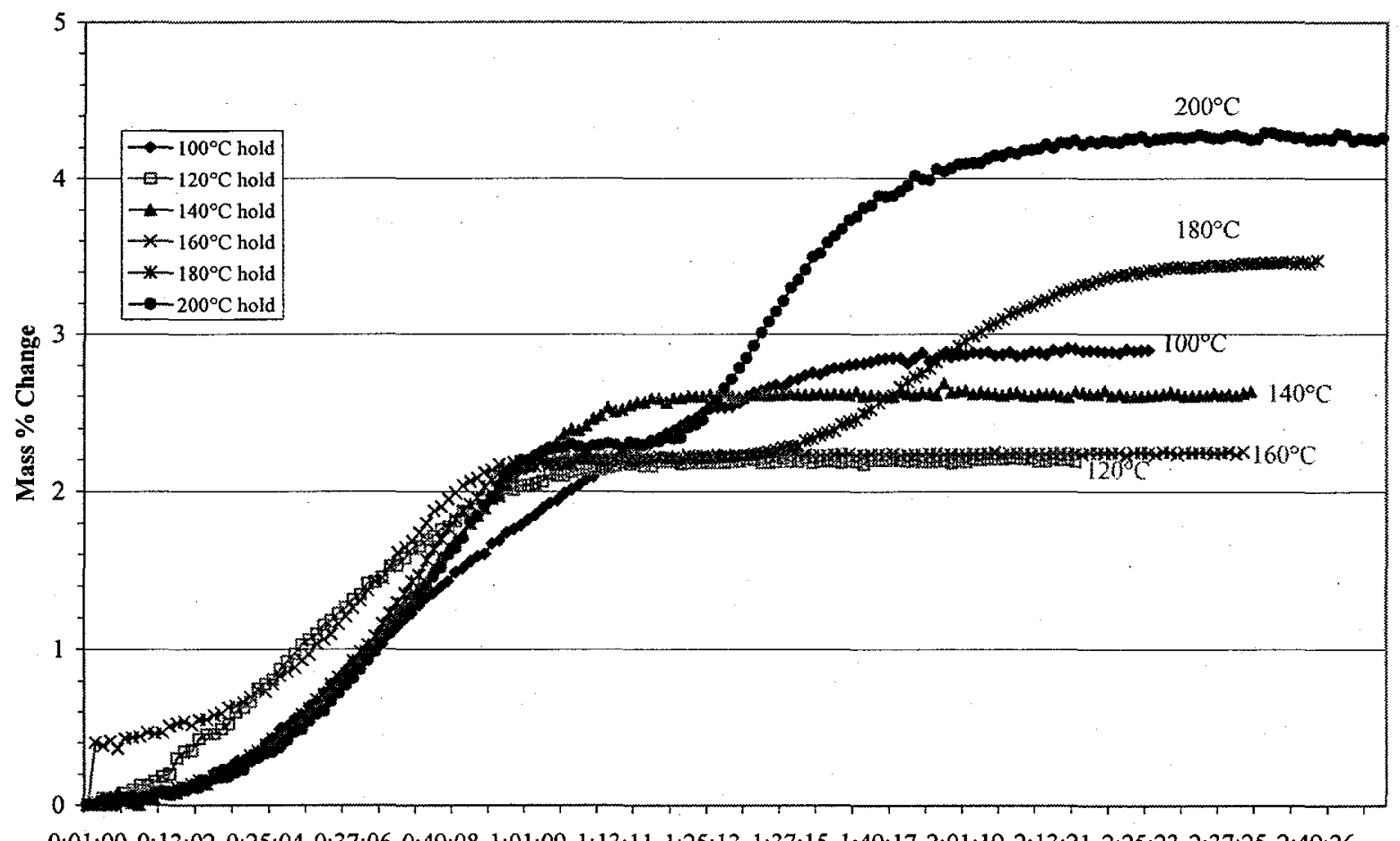

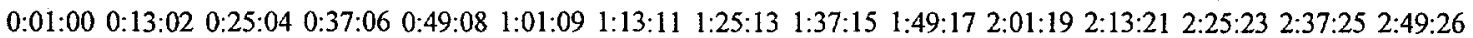

Elapsed Time (hours)

Figure 5.3. Low temperature hold (dehydration) experiments on pucks pressed from baseline ball-milled powders. 


\subsubsection{Determination of Thermal Gradients}

A method for measuring the puck temperature gradient was performed at LLNL. Full-size pucks were pressed with thermocouples contacting the puck surface and embedded in the core to measure temperature gradients during the sintering operation. Figure 5.4 shows puck surface and core temperatures during baseline schedule testing. As shown, the low temperature hold for binder burnout allows the puck surface and core temperatures to equilibrate. The temperature gradient between the puck surface and core during the ramp to the sintering temperature is in the range of $20^{\circ} \mathrm{C}$ at approximately one hour into the ramp to a maximum of approximately $80^{\circ} \mathrm{C}$ at 2.5 hours into the ramp. At the end of the ramp the temperature difference is approximately $30^{\circ} \mathrm{C}$. Equilibrium is reached after approximately thirty minutes into the sintering soak segment.

The puck surface temperature lags behind the furnace setpoint temperature at a maximum of $260^{\circ} \mathrm{C}$ at approximately one hour into the sintering ramp and then comes within $60^{\circ} \mathrm{C}$ of the setpoint sintering temperature after one hour of the soak segment. Puck temperature data after one hour of the sintering soak segment is not available because the thermocouples exceeded their useful life. It appears that the primary heat transfer limit is in heating of the puck surface and not the thermal gradient within the puck. This thermocoupled puck testing in conjunction with the BBO-FTIR tests will continue to aid in optimizing the sintering schedule.

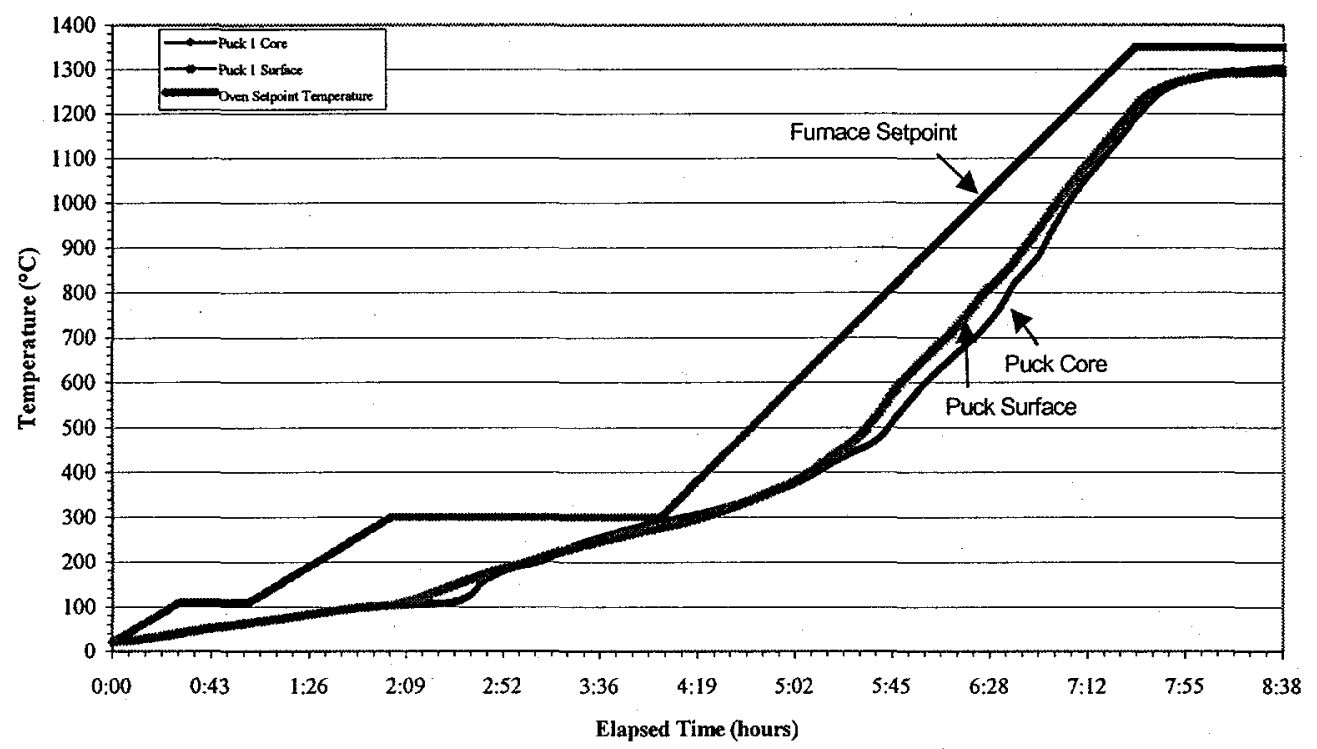

Figure 5.4. Thermocoupled puck using the baseline schedule.

\subsubsection{Effect of Agglomeration Methods}

As part of testing of the different granulation processes, TGA-DTA testing on powders and BBO-FTIR testing on full-size pucks were performed. The intent of the testing was to determine what effect, if any, the granulation process had on binder burnout. Some of the tests also involved direct comparisons of different binders. The five granulation methods that were compared include the blade granulator, GEMCO, pin mixer, fluid bed, and the roll compactor. The blade granulator, GEMCO, and pin mixer are all considered typical tumble agglomeration methods.

Most of the granulated powders compared in this section used hydroxy-propyl methylcellulose (HPMC) and/or PEG as the binder. The burnout behavior and the TGA-DTA for PEG were presented in 5.2.1 Baseline Tests. HPMC has a slightly different burnout behavior as shown in Figure 5.5. Approximately $90 \%$ of the material is decomposed between 300 and $400^{\circ} \mathrm{C}$, with the remaining material slowly outgassing as the temperature is heated to $700^{\circ} \mathrm{C}$. Therefore, it has a higher burnout temperature than PEG and is more similar in behavior to Acrawax (See Section 5.2.6). 


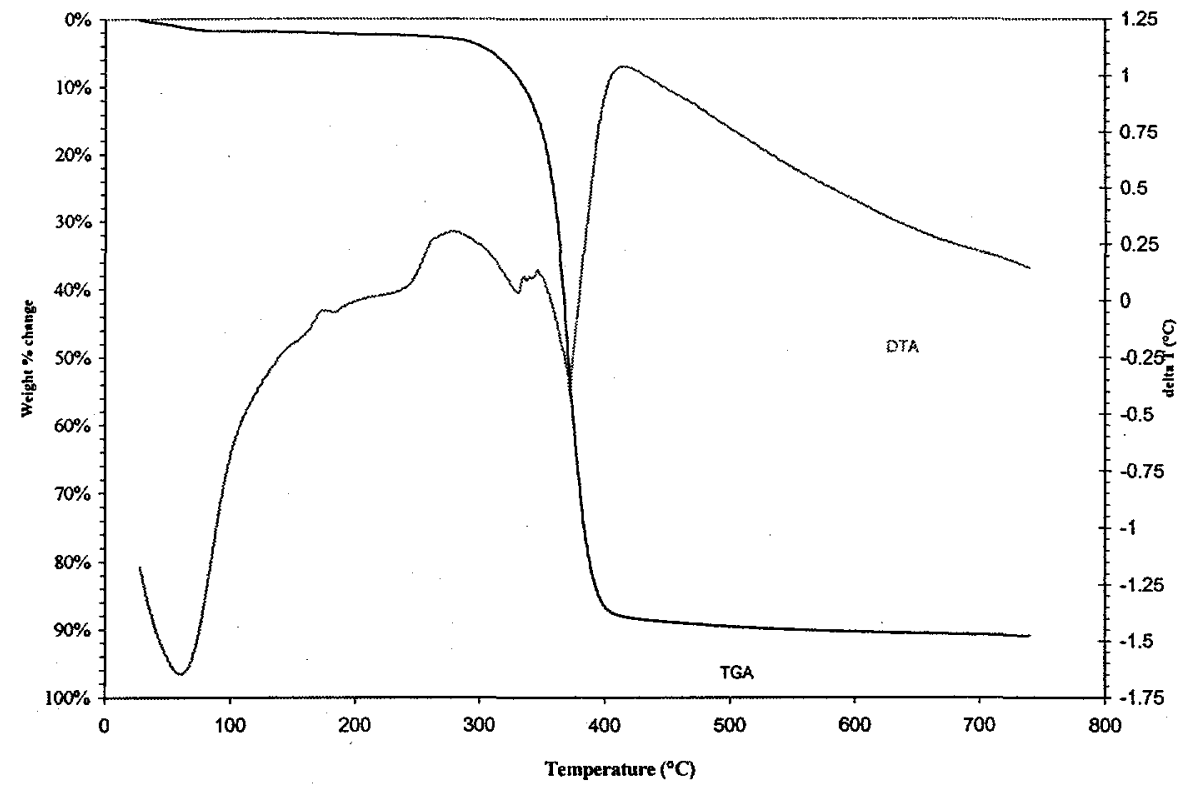

Figure 5.5. TGA-DTA for HPMC.

Several binder burnout tests were performed on full-size pucks made from each granulation method. A typical BBO-FTIR weight loss plot from the granulated material testing is shown in Figure 5.6. Figures 5.7 and 5.8 show the FTIR results for the offgassing behavior. A puck produced from the GEMCO powder (1 wt\% HPMC, $6.6 \mathrm{wt} \%$ water) is used for the example.

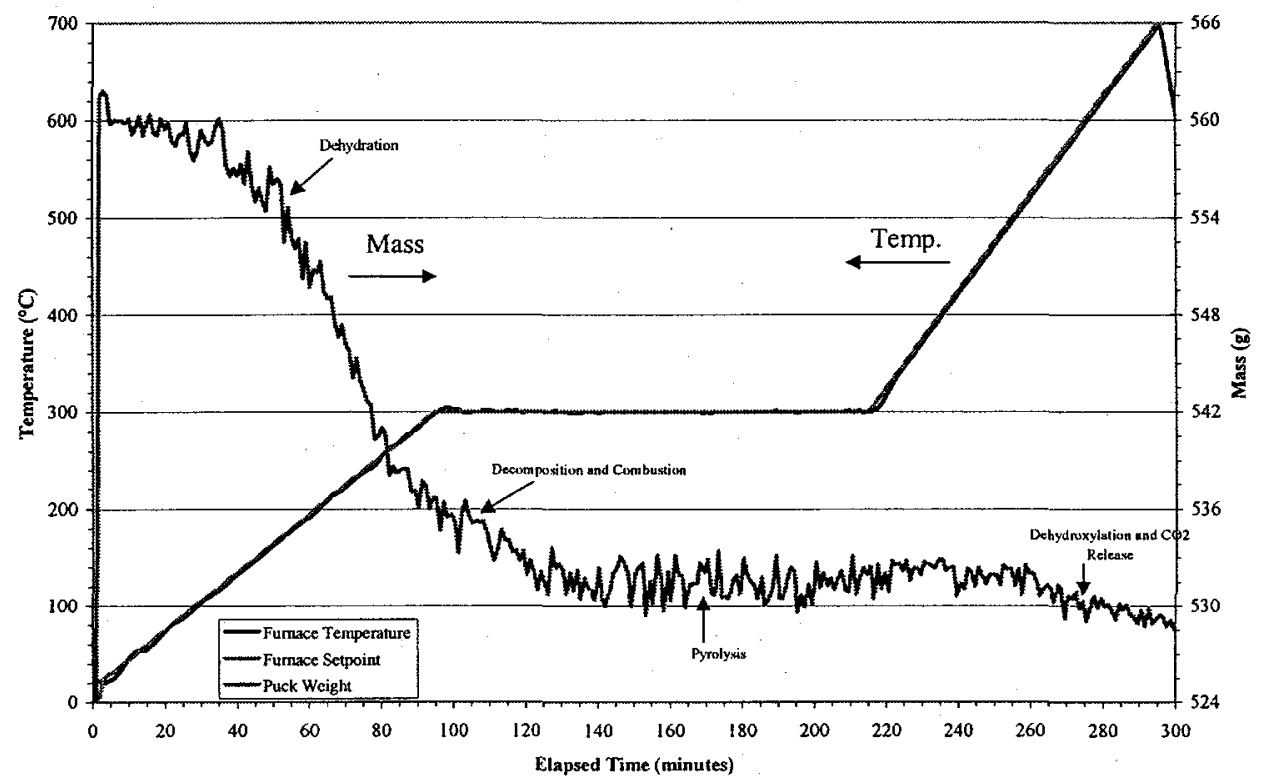

Figure 5.6. Binder burnout with puck produced from GEMCO powder. 


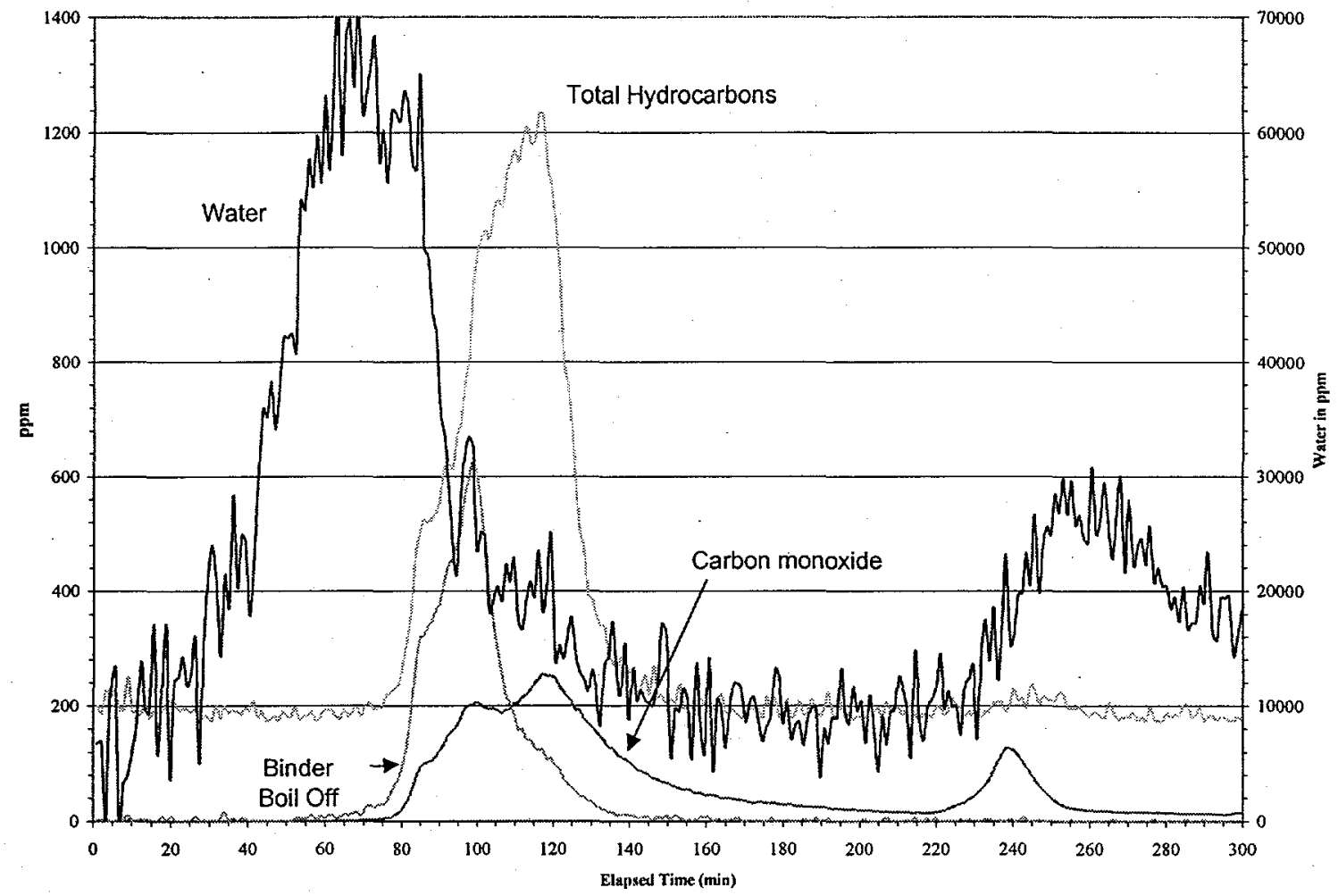

Figure 5.7. Offgas behavior for puck produced from GEMCO powder.

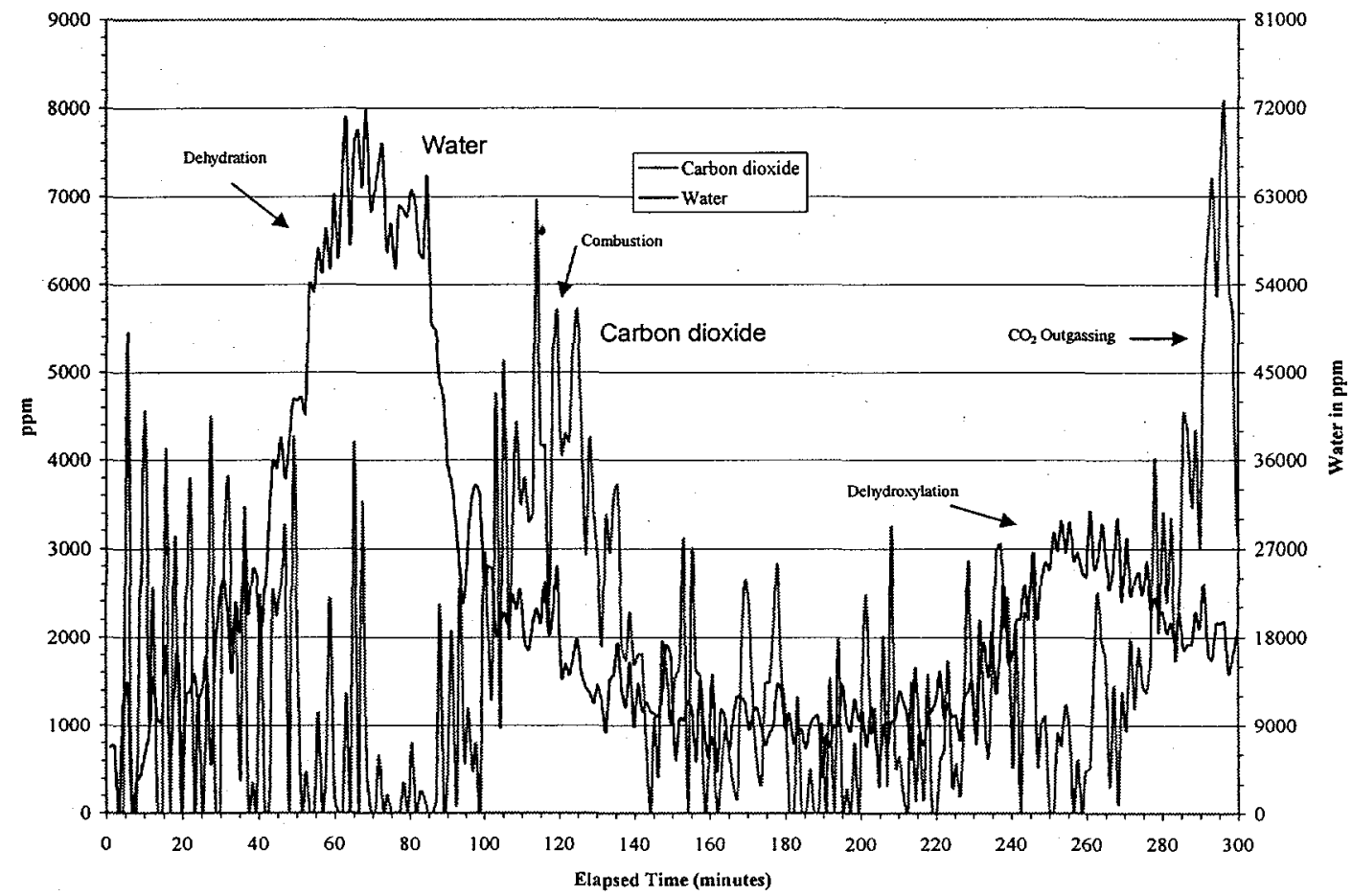

Figure 5.8. Offgas behavior for puck produced from GEMCO powder $\left(\mathrm{CO}_{2}\right.$ release). 
Heating of the GEMCO puck at $3^{\circ} \mathrm{C} / \mathrm{min}$ to $300^{\circ} \mathrm{C}$ showed weight loss starting at $\sim 100^{\circ} \mathrm{C}$ and continuing until approximately 45 minutes into the $300^{\circ} \mathrm{C}$ hold. FTIR indicates that water is the primary component being outgassed at the lower temperatures but becomes predominately organic species by the end of this range. The puck mass remains constant until about $450^{\circ} \mathrm{C}$ in the second ramp when waters of hydration and $\mathrm{CO}_{2}$ outgas which causes additional weight loss. Weight loss continued as the furnace was shut off at $700^{\circ} \mathrm{C}$. As with the baseline powders, differences in weight loss between GEMCO powder and pucks were observed. A comparison of the burnout behavior of GEMCO powder + binder ( $1 \mathrm{wt} \%$ HPMC, $10 \mathrm{wt} \%$ water), and pressed GEMCO powder with binder (1 wt\% HPMC, $6.6 \mathrm{wt} \%$ water) is shown in Table 5.2.

Table 5.2

TGA-DTA for GEMCO Powder and Puck

\begin{tabular}{|c|c|c|c|}
\hline \multicolumn{2}{|c|}{$\begin{array}{c}\text { TGA of } \\
\text { GEMCO Powder } \\
\text { (1 wt } \% \text { HPMC, } 10 \text { wt } \% \text { water })\end{array}$} & \multicolumn{2}{|c|}{$\begin{array}{c}\text { BBO-FTIR (Baseline Schedule) of } \\
\text { GEMCO Puck, } \\
\text { (1 wt \% HPMC, 6.6 wt \% water) }\end{array}$} \\
\hline Temperature Range & Wt. Change & Temperature Range & Wt. Change \\
\hline $\begin{array}{c}\mathrm{RT}-70^{\circ} \mathrm{C} \\
250-320^{\circ} \mathrm{C} \\
420-450^{\circ} \mathrm{C} \\
450-550^{\circ} \mathrm{C} \\
550-700^{\circ} \mathrm{C}\end{array}$ & $\begin{array}{l}-7.3 \% \\
-0.7 \% \\
-0.3 \% \\
+0.1 \% \\
-4.4 \%\end{array}$ & $\begin{array}{c}\mathrm{RT}-300^{\circ} \mathrm{C} \\
45 \text { min. into hold @ } 300^{\circ} \mathrm{C} \\
530-700^{\circ} \mathrm{C} \\
>700^{\circ} \mathrm{C}\end{array}$ & $\begin{array}{c}-4.5 \% \\
-1.0 \% \\
-0.5 \% \\
\text { continued wt. loss }\end{array}$ \\
\hline
\end{tabular}

The three tumble agglomeration methods all had similar binder burnout behavior. For the tests performed, the binder was $\sim 1 \%$ HPMC with $\sim 10 \%$ water. All pucks had steady burnout to $300^{\circ} \mathrm{C}$ and reached equilibrium during the hold. Weight loss occurred again at $450^{\circ} \mathrm{C}$ in the second ramp in all cases. The short plateau in the 200 to $240^{\circ} \mathrm{C}$ range observed in the baseline PEG pucks (Figure 5.1) was not observed in the tumble agglomeration test pucks, which may be due to more overlap of the HPMC burnout with water burnout or differences in particle size and porosity in the green pucks.

Fluid bed powder had slightly different powder characteristics since the powder morphology is slightly different and the moisture content is much less. However, some of the pucks showed similar binder burnout characteristics to tumble agglomerated powder. Some also had the plateau seen for the baseline wet ball milled powder with a secondary higher temperature plateau $\left(>560^{\circ} \mathrm{C}\right)$. The fluid bed pucks burnout behavior were also shown to be dependent on pressing pressure.

Finally, the roll compactor powder was expected to, and did, behave differently due to the lower moisture content and the higher pressures used to agglomerate the powders. The pucks also required higher compaction pressures and typically contained higher organic binder contents. In general, all pucks showed a mass loss rate change in the range of 210 to $270^{\circ} \mathrm{C}$ before reaching near equilibrium during the $300^{\circ} \mathrm{C}$ hold. As the temperature rose above $400^{\circ} \mathrm{C}$, mass loss rates changed and, depending on the organic additive, additional plateaus or rate changes were observed. All of these pucks used varying amounts of HPMC and/or PEG, but no direct correlation to the content and outgassing behavior was seen for the full-size pucks.

\subsubsection{Effect of Grinding Aids}

For the granulation testing, all powders were prepared using the attritor mill for blending and mixing. When the attritor mill is used, a dispersant must be added during mixing to assist with discharge from the mill. Polyolefin wax (Acumist 12) and ethylene bisstearamide (Acrawax C) have been used successfully for this operation. TGA-DTA of Polyolefin and Acrawax show that both decompose between approximately 250 and $525^{\circ} \mathrm{C}$. Table 5.3 shows a comparison of TGA-DTA data of ball milled powder with no dispersant versus attritor milled powder containing 3 $\mathrm{wt} \%$ polyolefin as a dispersant. Both powders contained $5 \mathrm{wt} \% \mathrm{PEG}$ as binder. The attritor mill results in a smaller particle size compared to ball milling. The particle size would likely change the rate of burnout but is not expected 
to have an effect on the actual burnout amount. As shown, the temperature ranges of burnout are very similar. The biggest difference is the higher amount of weight loss in the 250 to $400^{\circ} \mathrm{C}$ range for the attritor milled powder, consistent with the weight loss range for the dispersant by itself. Therefore, the use of a dispersant introduces another region in the binder burnout process where the schedule has to be developed to ensure puck integrity.

Table 5.3

TGA-DTA for Ball Milled versus Attritor Milled Powder

\begin{tabular}{|c|c|c|c|}
\hline \multicolumn{2}{|c|}{$\begin{array}{c}\text { Ball Milled } \\
\text { (5 wt } \% \text { PEG, no polyolefin) }\end{array}$} & \multicolumn{2}{|c|}{$\begin{array}{c}\text { Attritor Milled } \\
\text { (5 wt } \% \text { PEG, } 3 \text { wt } \% \text { polyolefin) }\end{array}$} \\
\hline Temperature Range & Wt. Change & Temperature Range & Wt. Change \\
\hline $195-300^{\circ} \mathrm{C}$ & $-2.7 w t \%$ & $165-280^{\circ} \mathrm{C}$ & $-2.2 w t \%$ \\
\hline $425-450^{\circ} \mathrm{C}$ & $-0.5 w t \%$ & $280-390^{\circ} \mathrm{C}$ & $-2.5 w t \%$ \\
\hline $450-550^{\circ} \mathrm{C}$ & +0.5 wt\% & $390-540^{\circ} \mathrm{C}$ & +0.3 wt $\%$ \\
\hline $550-680^{\circ} \mathrm{C}$ & $-4.0 w t \%$ & $540-700^{\circ} \mathrm{C}$ & $-3.6 \mathrm{wt} \%$ \\
\hline
\end{tabular}

\subsubsection{Feed Composition Effects}

Much of the plutonium to be immobilized will contain some amount of impurities, which may have an effect on the sintering behavior of the ceramic form. Therefore, TGA-DTA and BBO-FTIR studies were performed on selected impurity composition powders to determine impurity effects. The compositions used were the hafnium/cerium/cerium versions of A-9 and B3-13 formulations, which are the average impurity cases. TGA data from the baseline powder (A-0 formulation) is compared to data from the A-9 composition powder in Table 5.4. The A-9 powder shows a very gradual weight loss from the onset of heating, compared to distinct larger weight loss regions with the A-0 formulation, which do not start until $\sim 195^{\circ} \mathrm{C}$. For A-9, the largest amount of loss occurs in the $210-385^{\circ} \mathrm{C}$ range, while the $\mathrm{A}-0$ formulation has two large loss regions (i.e., $195-300^{\circ} \mathrm{C}$ and 550 to $680^{\circ} \mathrm{C}$ ).

Table 5.4

TGA Data for A-0 and A-9 Compositions

\begin{tabular}{cccc}
\hline \multicolumn{2}{c}{ A-0 Composition } & \multicolumn{2}{c}{ A-9 Composition } \\
Temperature Range & Wt. Change & Temperature Range & Wt. Change \\
\hline $195-300^{\circ} \mathrm{C}$ & $-2.7 \mathrm{wt} \%$ & $\mathrm{RT}-180^{\circ} \mathrm{C}$ & $-0.4 \mathrm{wt} \%$ \\
$425-450^{\circ} \mathrm{C}$ & $-0.5 \mathrm{wt} \%$ & $180-210^{\circ} \mathrm{C}$ & $-0.5 \mathrm{wt} \%$ \\
$450-550^{\circ} \mathrm{C}$ & $+0.5 \mathrm{wt} \%$ & $210-385^{\circ} \mathrm{C}$ & $-1.1 \mathrm{wt} \%$ \\
$550-680^{\circ} \mathrm{C}$ & $-4.0 \mathrm{wt} \%$ & $515-575^{\circ} \mathrm{C}$ & $+0.1 \mathrm{wt} \%$ \\
& & $575-680^{\circ} \mathrm{C}$ & $-0.2 \mathrm{wt} \%$ \\
\hline
\end{tabular}

BBO-FTIR tests were also performed on pucks of the A-0, A-9, and B3-13 compositions using the baseline schedule (i.e., heat at $3^{\circ} \mathrm{C} / \mathrm{min}$ to $300^{\circ} \mathrm{C}$ and hold for 2 hours). Very similar behavior to the baseline composition was observed. The biggest difference in the mass loss was at $\sim 240^{\circ} \mathrm{C}$. While the baseline composition had a plateau from 200 to $240^{\circ} \mathrm{C}$, the impurity composition continued to lose weight through this region and had a sharp slope change (i.e., mass rate change) at $240^{\circ} \mathrm{C}$. The rates of weight loss in the pucks were consistent with rate loss behavior in the different powders. Both the TGA-DTA and the binder burnout puck data for the A-9 formulation showed a gradual loss rate. The biggest weight loss occurred above $240^{\circ} \mathrm{C}$ for the puck, which would be consistent with the loss region between 210 to $385^{\circ} \mathrm{C}$ for the powder when matrix effects are taken into account. 


\subsection{Conclusions}

Based on the binder burnout tests, the following conclusions can be made:

1) The weight loss behavior of binders differs between the organic material, ceramic powder containing the organic material, and full-size pucks.

2) Process parameters (e.g. granulation methods, pressing pressure, binder dispersal, and binder type, etc.) have an important influence on puck offgassing and low temperature expansion behavior and, thus, the binder burnout schedule and puck integrity.

3) Mass transfer and heat transfer (heating of the puck surface and to a lesser degree the internal thermal gradient) limitations are important parameters that impact cracking but can be controlled by the ramp rate.

4) Critical burnout temperature regions can be defined using the thermal analysis tools developed in this program.

5) Optimization of the ramp rate in the burnout regions to control product quality can be accomplished using the thermal analysis tools to determine the maximum heating rates, proper low temperature holds and minimum soak times to ensure product quality.

\subsection{Future Work}

Most recently a tumble granulator was selected as the baseline granulation equipment. Therefore, binder burnout testing is currently being performed on GEMCO material. The entire granulation process and the associated parameters are still being optimized. It is realized that optimization of the granulation process will likely change the behavior of the green puck during binder burnout. However, it has been demonstrated that the proper tools have been developed to optimize the burnout schedule as the powder processing methods are finalized. In addition, efforts will be made to develop a BBO-FTIR furnace capability above $700^{\circ} \mathrm{C}$ to define the full binder burnout schedule. Further analysis of offgas and assessment of flammability hazards will be conducted. The relevant quantities of exact chemical species will be evaulated for potential flammability concerns. That data shall serve as input for design of offgas handling equipment, if necessary.

\subsection{CLEMSON PROTOTYPIC TEST FACILITY AND LLNL PU CERAMIFICATION TEST FACILITY}

A prototype process test facility is currently being designed for the Clemson Environmental Technology Laboratory (CETL) to perform full-scale testing of the ceramic system using surrogate materials and uranium to confirm and optimize the physical process operations. This capability is needed to ensure that the as-designed plant equipment will effectively condition, press, and sinter oxide powders in the configuration intended for the immobilization plant. Data obtained from the current sintering studies are being used to design the prototype sintering furnace for the CETL. Full-load testing (pucks and furnace trays) with the prototypical sintering furnace will aid in validating and optimizing the sintering schedule.

Testing of full-size plutonium pucks will also be performed at the LLNL Pu Ceramification Test Facility (PuCTF). In the PuCTF, the critical ceramic processing steps will be coupled, optimized, and demonstrated using subproduction scale, but functionally prototypic, equipment. The PuCTF will couple subscale milling, blending, and granulation equipment for the actinide milling and blending operations with a full-scale automated press and a laboratory-scale sintering furnace. The equipment in this integrated glovebox system will be used to confirm critical operations and to assess maintenance issues (powder transfer, dust control, material hold-up, material accountability, operator radiation dose control).

Based on studies to date, the full-scale furnace for the CETL should be designed to operate at a nominal sintering temperature range of $1275-1400^{\circ} \mathrm{C}$. The maximum furnace temperature capability should be designed in the range of $1600-1700^{\circ} \mathrm{C}$ to provide adequate margin between the expected normal operating sintering temperature and maximum capability. An adequate margin is needed to ensure that reduction in maximum capability due to heating element degradation with continuous normal operating use remains above the normal operating sintering temperature. The baseline testing will be performed in air, therefore, molybdenum disilicide heating elements provide optimal operating performance and life at these temperatures based on industry operating experience. The furnace should also be designed to meet the current baseline sintering schedule of: 1) heating to $300^{\circ} \mathrm{C}$ at $3^{\circ} \mathrm{C} / \mathrm{min}$, 
2) holding at $300^{\circ} \mathrm{C}$ for $2 \mathrm{~h}, 3$ ) heating to the specified sintering temperature at $5^{\circ} \mathrm{C} / \mathrm{min}, 4$ ) holding at the sintering temperature for the specified time, and then 5) cooling to room temperature at $5^{\circ} \mathrm{C} / \mathrm{min}$. The control system should provide for programming of a thermal cycle profile with a minimum of eight time/temperature setpoints to allow for testing additional hold or ramp regions.

\subsection{ACKNOWLEDGEMENTS}

The authors gratefully acknowledge the following individuals for their significant and invaluable help in performing this work:

- Small-Scale Plutonium Sintering Studies

James Clark, WSRC

Don Burge, WSRC

Michael Lee, WSRC

John Pareizs, WSRC

Patricia Toole, WSRC

- Powder TGA/DTA

Paul Korinko, WSRC

- HT-XRD, XRD

Art Jurgensen, WSRC

David Missimer, WSRC

BBO-FTIR

Frank Beckett, LLNL

Bill Biehl, LLNL

Steve Williams, LLNL

Keith Willfinger, LLNL

\subsection{REFERENCES}

1. Fissile-Materials Storage and Disposition Programmatic Environmental Impact Statement Record of Decision, Storage and Disposition Final PEIS, 62 Federal Register 3014, January 14, 1997.

2. S. G. Cochran, W. H. Dunlop, T. A. Edwards, L. M. MacLean, T. H. Gould, Jr., "Fissile Material Disposition Program-Final Immobilization Form Assessment and Recommendation." UCCRL-ID-128705, October 3, 1997.

3. L. Gray and T. H. Gould, Jr., "Immobilization Technology Down-Selection Radiation Barrier Approach," UCRL-ID-127320, May 23, 1997.

4. W. Stein, V. Sahai, T. Kan, J. Marra and J. Vienna, "Simulation and Testing of Pouring High

Level Waste Glass into Canisters Containing Immobilized Plutonium Forms," Proceedings of

the Third Topical Meeting on DOE Spent Nuclear Fuel and Fissile Materials Management, American Nuclear Society, LaGrange Park, IL, 1998.

5. B. B. Ebbinghaus, C. A. Herman, L. W. Gray and H. F. Shaw, "Plutonium Immobilization Project Baseline Formulation," Lawrence Livermore National Laboratory, UCRL-ID-133089, PIP-99-012, Livermore, CA, 1999.

6. US Department of Energy, Plutonium Immobilization Product Specifications - DRAFT, 1999.

7. US Department of Energy, Waste Acceptance Product Specifications, December 1996.

8. A. Jurgensen, D. Missimer, personal communication, April 15, 1999, "Plutonium Immobilization Project Development and Testing Technical Progress Report - Section 6.4 Puck NDE for Process Control," PIP-99071 , May 1999.

9. C. A. Herman, B. Biehl, F. Beckett, S. Williams, "Summary of Impurity Composition Studies with Full-Size Pucks," Lawrence Livermore National Laboratory Report, SMP-046-99.

10. K. M. Marshall, J. W. Congdon, "A Process for Immobilizing Plutonium," Environmental Issues and Waste Management Technologies in the Ceramic and Nuclear Industries V, American Ceramic Society, To be published, Spring 2000. 
11. A. J. Bakel, E. C. Buck, V. N. Zyryanov, C. J. Mertz, and D. B. Chamberlain, "Characterization and Corrosion Behavior of Hafnium-Cerium-Uranium Ceramics Containing Impurities," ANL-99/xx, June 1999.

12. A. J. Bakel, "Corrosion of Titanate Ceramics - Rates and Effects," Argonne National Laboratory Presentation at Lawrence Livermore National Laboratory, September, 1998.

13. P. Walls, "Final Report on Initial Samples Supplied by LLNL for Task 3.3 Binder Burnout and Sintering Schedule Optimisation," ANSTO report R99m003, January 4, 1999.

14. L. Pennisi, "The Firing Process," Engineered Materials Handbook, Volume 4, Ceramics and Glasses, pp. 255 259. 
APPENDIX A

Weight Loss Data from Preliminary TGA Studies of Binder Only and Binder + Precursor Powders

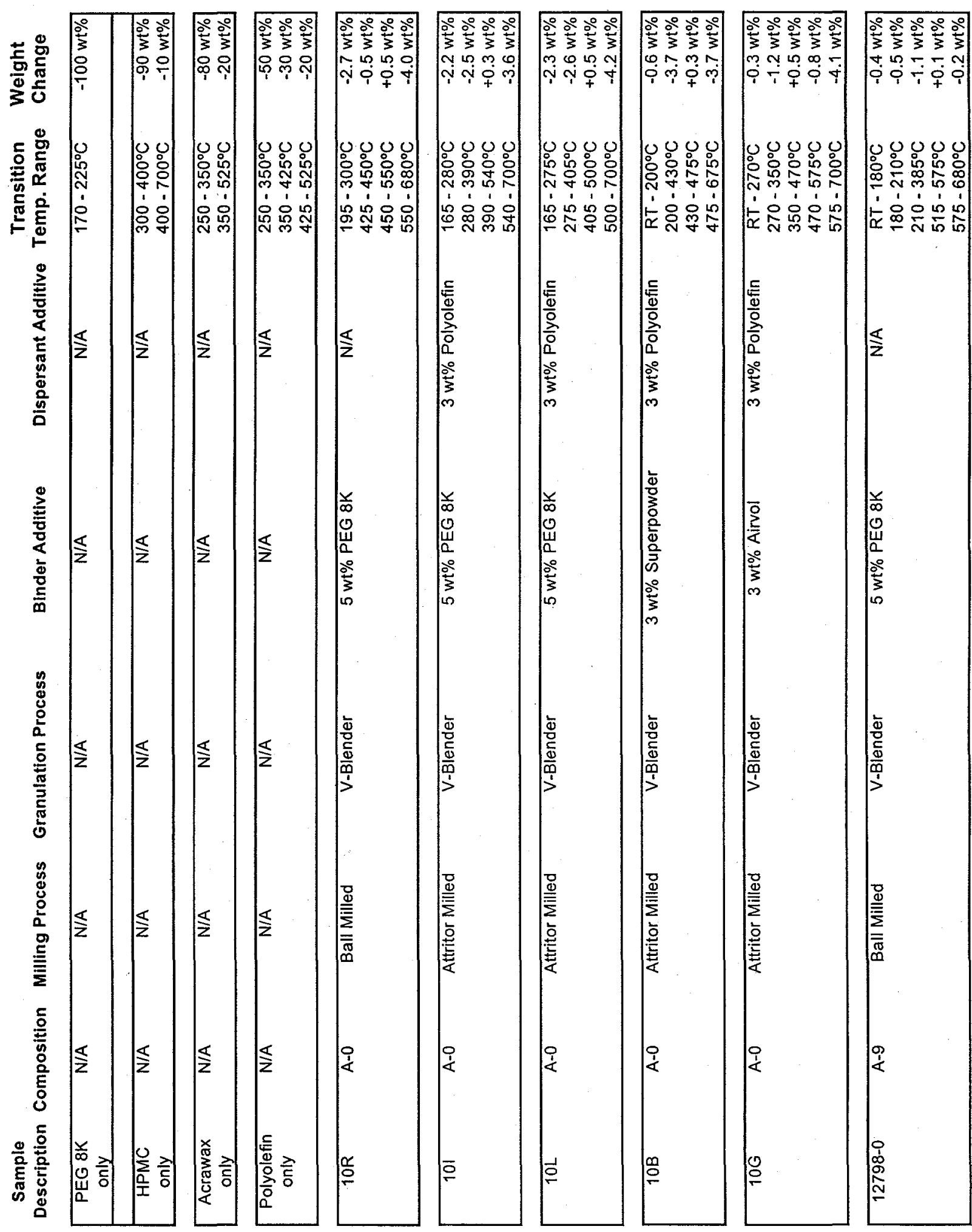


APPENDIX A

Weight Loss Data from Preliminary TGA Studies of

Binder Only and Binder + Precursor Powders (Continued)

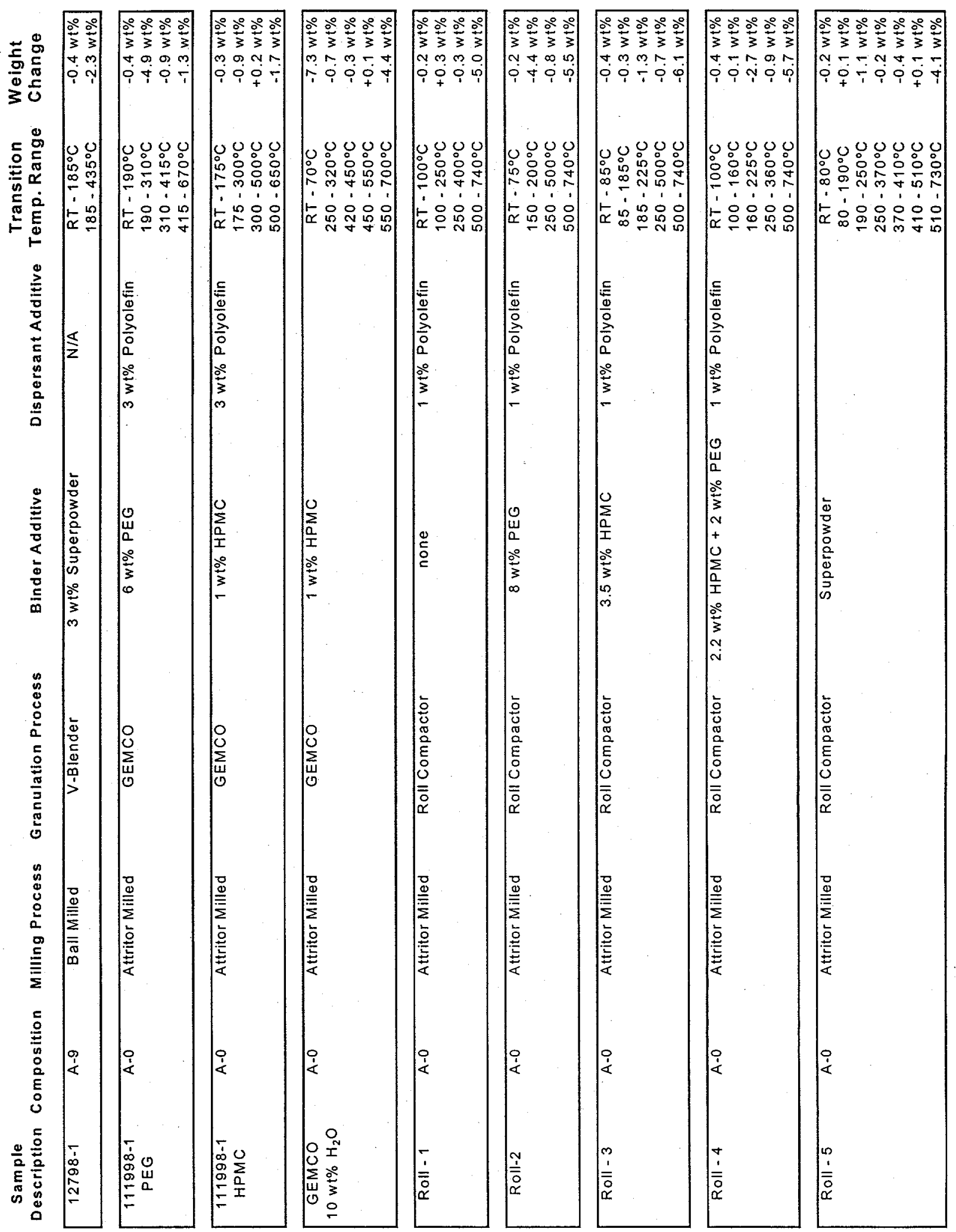


APPENDIX B

Weight Loss Data From Binder Burnout Testing Performed To Date

Phase 1 of Testing

Baseline Wet Ball Milled Process with 5 wt\% PEG

\begin{tabular}{|c|c|c|c|c|c|}
\hline $\begin{array}{c}\text { Puck } \\
\#\end{array}$ & Schedule Tested & Variable & \begin{tabular}{|c|} 
Transition \\
Temperature \\
Ranges
\end{tabular} & $\begin{array}{l}\text { Associated } \\
\text { Weight } \\
\text { Changes }\end{array}$ & $\begin{array}{l}\text { Associated } \\
\text { Hold Time* }\end{array}$ \\
\hline \multirow{2}{*}{947} & \multirow{2}{*}{$3^{\circ} \mathrm{C} / \mathrm{min}$ to $300^{\circ} \mathrm{C}, 2$ hour hold } & \multirow{2}{*}{ Baseline hold temperature } & $50-210^{\circ} \mathrm{C}$ & $-2.5 w t \%$ & $\mathrm{~N} / \mathrm{A}$ \\
\hline & & & $250-300^{\circ} \mathrm{C}$ & $-3.3 w t \%$ & $10 \mathrm{~min}$. \\
\hline \multirow{4}{*}{1240} & \multirow{4}{*}{$\begin{array}{l}3^{\circ} \mathrm{C} / \min \text { to } 300^{\circ} \mathrm{C}, 2 \text { hour } \\
\text { hold, } 5^{\circ} \mathrm{C} / \min \text { to } 700^{\circ} \mathrm{C}\end{array}$} & \multirow{4}{*}{ Repeat of 947 with FTIR } & $50-200^{\circ} \mathrm{C}$ & $-2.4 w t \%$ & N/A \\
\hline & & & $240-300^{\circ} \mathrm{C}$ & $-2.8 w t \%$ & N/A \\
\hline & & & $480-620^{\circ} \mathrm{C}$ & $-1.0 w t \%$ & N/A \\
\hline & & & $620-700^{\circ} \mathrm{C}$ & $-0.2 w t \%$ & N/A \\
\hline \multirow[b]{2}{*}{830} & \multirow{2}{*}{$3^{\circ} \mathrm{C} / \mathrm{min}$ to $350^{\circ} \mathrm{C}, 2$ hour hold } & \multirow{2}{*}{ Binder hold temperature } & $50-200^{\circ} \mathrm{C}$ & $-2.5 w t \%$ & N/A \\
\hline & & & $240-300^{\circ} \mathrm{C}$ & $-2.0 w t \%$ & N/A \\
\hline \multirow{2}{*}{831} & \multirow{2}{*}{$3^{\circ} \mathrm{C} / \mathrm{min}$ to $400^{\circ} \mathrm{C}, 2$ hour hold } & \multirow{2}{*}{ Binder hold temperature } & $50-200^{\circ} \mathrm{C}$ & $-2.4 w t \%$ & N/A \\
\hline & & & $240-300^{\circ} \mathrm{C}$ & $-2.9 w t \%$ & N/A \\
\hline \multirow{3}{*}{842} & \multirow{3}{*}{$3^{\circ} \mathrm{C} / \min$ to $450^{\circ} \mathrm{C}, 2$ hour hold } & \multirow{3}{*}{ Binder hold temperature } & $50-200^{\circ} \mathrm{C}$ & $-2.5 w t \%$ & N/A \\
\hline & & & $240-300^{\circ} \mathrm{C}$ & $-2.8 \mathrm{wt} \%$ & N/A \\
\hline & & & hold@450C & $-0.5 w t \%$ & $20-120 \mathrm{~min}$ \\
\hline \multirow{3}{*}{854} & \multirow{3}{*}{$3^{\circ} \mathrm{C} / \mathrm{min}$ to $500^{\circ} \mathrm{C}, 2$ hour hold } & \multirow{3}{*}{ Binder hold temperature } & $50-200^{\circ} \mathrm{C}$ & $-2.6 \mathrm{wt} \%$ & N/A \\
\hline & & & $240-300^{\circ} \mathrm{C}$ & $-2.8 w t \%$ & N/A \\
\hline & & & $480-500^{\circ} \mathrm{C}$ & $-0.7 w t \%$ & $60 \mathrm{~min}$ \\
\hline \multirow{3}{*}{890} & \multirow{3}{*}{$3^{\circ} \mathrm{C} / \mathrm{min}$ to $700^{\circ} \mathrm{C}$, no hold } & \multirow{3}{*}{ Necessity of hold } & $50-210^{\circ} \mathrm{C}$ & $-2.4 w t \%$ & N/A \\
\hline & & & $250-300^{\circ} \mathrm{C}$ & $-3.0 \mathrm{wt} \%$ & N/A \\
\hline & & & $480-600^{\circ} \mathrm{C}$ & $-0.6 \mathrm{wt} \%$ & N/A \\
\hline 905 & $3^{\circ} \mathrm{C} / \mathrm{min}$ to $100^{\circ} \mathrm{C}, 2$ hour hold & Dehydration hold temperature & $45-100^{\circ} \mathrm{C}$ & $-2.9 \mathrm{wt} \%$ & $90 \mathrm{~min}$. \\
\hline 906 & $3^{\circ} \mathrm{C} / \mathrm{min}$ to $120^{\circ} \mathrm{C}, 2$ hour hold & Dehydration hold temp & $70-120^{\circ} \mathrm{C}$ & $-2.2 w t \%$ & $55 \mathrm{~min}$. \\
\hline 907 & $3^{\circ} \mathrm{C} / \mathrm{min}$ to $140^{\circ} \mathrm{C}, 2$ hour hold & Dehydration hold temperature & $45-140^{\circ} \mathrm{C}$ & $-2.6 w t \%$ & $30 \mathrm{~min}$. \\
\hline \multirow[b]{2}{*}{909} & \multirow{2}{*}{$3^{\circ} \mathrm{C} / \mathrm{min}$ to $160^{\circ} \mathrm{C}, 2$ hour hold } & & $40-110^{\circ} \mathrm{C}$ & $-0.7 w t \%$ & N/A \\
\hline & & Dehydration hold temperature & $110-160^{\circ} \mathrm{C}$ & $-1.5 \mathrm{wt} \%$ & $20 \mathrm{~min}$. \\
\hline & & & $40-80^{\circ} \mathrm{C}$ & $-0.2 w t \%$ & N/A \\
\hline 913 & $3^{\circ} \mathrm{C} / \mathrm{min}$ to $180^{\circ} \mathrm{C}, 2$ hour hold & Dehydration hold temperature & $80-180^{\circ} \mathrm{C}$ & $-2.0 w t \%$ & $10 \mathrm{~min}$. \\
\hline & & & hold@180C & $-1.3 w t \%$ & $40-90 \mathrm{~min}$. \\
\hline & & & $45-95^{\circ} \mathrm{C}$ & $-0.3 \mathrm{wt} \%$ & N/A \\
\hline 967 & $3^{\circ} \mathrm{C} / \mathrm{min}$ to $180^{\circ} \mathrm{C}, 3$ hour hold & Dehydration hold time & $95-180^{\circ} \mathrm{C}$ & $-1.8 w t \%$ & $20 \mathrm{~min}$. \\
\hline & & & hold@180 $180^{\circ} \mathrm{C}$ & $-1.6 w t \%$ & $49-110 \mathrm{~min}$. \\
\hline & & & $50-100^{\circ} \mathrm{C}$ & $-0.2 w t \%$ & N/A \\
\hline 928 & $3^{\circ} \mathrm{C} / \mathrm{min}$ to $200^{\circ} \mathrm{C}, 2$ hour hold & Dehydration hold temperature & $100-200^{\circ} \mathrm{C}$ & $-2.1 w t \%$ & N/A \\
\hline & & & hold @ $200^{\circ} \mathrm{C}$ & $-1.9 w t \%$ & $25-75 \mathrm{~min}$. \\
\hline & & & $50-180^{\circ} \mathrm{C}$ & $-2.2 w t^{0} \%$ & $10 \mathrm{~min}$. \\
\hline 948 & 00 & Necessity of binder hold & hold@180 & $-1.8 w t \%$ & $45-120$ min. \\
\hline & & & $300-600^{\circ} \mathrm{C}$ & $-2.0 w t \%$ & N/A \\
\hline & & & $50-110^{\circ} \mathrm{C}$ & $-0.2 w t \%$ & N/A \\
\hline N/A & $3^{\circ} \mathrm{C} / \mathrm{min}$ to $300^{\circ} \mathrm{C}, 2$ hour hold & Composition (B3-13) & $110-245^{\circ} \mathrm{C}$ & $-1.5 w t \%$ & N/A \\
\hline & & & $245-300^{\circ} \mathrm{C}$ & $-2.7 w t \%$ & $10 \mathrm{~min}$. \\
\hline & & & $50-240^{\circ} \mathrm{C}$ & $-0.9 w t \%$ & N/A \\
\hline & & & $240-300^{\circ} \mathrm{C}$ & $-3.6 \mathrm{wt} \%$ & N/A \\
\hline 1241 & 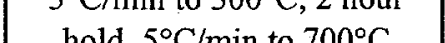 & Composition (A-9) & $420-490^{\circ} \mathrm{C}$ & $-0.2 w t \%$ & N/A \\
\hline & & & $490-570^{\circ} \mathrm{C}$ & $-0.5 w t \%$ & N/A \\
\hline & & & $640-700^{\circ} \mathrm{C}$ & $-0.3 w t \%$ & N/A \\
\hline N/A & $3^{\circ} \mathrm{C} / \mathrm{min}$ to $300^{\circ} \mathrm{C}, 2$ hour hold & Binder composition (PVA) & $20-160^{\circ} \mathrm{C}$ & $-1.5 w t \%$ & N/A \\
\hline
\end{tabular}

*Hold times represent the time at the upper temperature or the time at temperature before change occurs. 


\section{APPENDIX B (Continued) \\ Weight Loss Data From Binder Burnout Testing Performed To Date \\ Phase 2 of Testing \\ Granulated Materials}

\begin{tabular}{|c|c|c|c|c|c|}
\hline Puck \# & Schedule Tested & Variable & $\begin{array}{c}\text { Transition } \\
\text { Temperature } \\
\text { Ranges } \\
\end{array}$ & $\begin{array}{c}\text { Associated } \\
\text { Weight } \\
\text { Changes } \\
\end{array}$ & $\begin{array}{l}\text { Associated } \\
\text { Hold Time* }\end{array}$ \\
\hline \multirow[b]{2}{*}{1001} & \multirow[b]{2}{*}{$3^{\circ} \mathrm{C} / \min$ to $300^{\circ} \mathrm{C}, 2$ hour hold } & \multirow{2}{*}{ Blade Granulator } & $\mathrm{RT}-136^{\circ} \mathrm{C}$ & -0.7 wt $\%$ & N/A \\
\hline & & & $136-300^{\circ} \mathrm{C}$ & $-5.3 w t \%$ & $15 \mathrm{~min}$. \\
\hline \multirow{5}{*}{1085} & \multirow{5}{*}{$\begin{array}{c}3^{\circ} \mathrm{C} / \mathrm{min} \text { to } 300^{\circ} \mathrm{C}, 2 \text { hour hold, } 5^{\circ} \mathrm{C} / \mathrm{min} \text { to } \\
700^{\circ} \mathrm{C}\end{array}$} & \multirow{5}{*}{ Blade Granulator } & $\mathrm{RT}-100^{\circ} \mathrm{C}$ & $-0.4 w t \%$ & N/A \\
\hline & & & $100-300^{\circ} \mathrm{C}$ & $-9.4 w t \%$ & $10 \mathrm{~min}$. \\
\hline & & & $300-450^{\circ} \mathrm{C}$ & $+0.2 w t \%$ & $110 \mathrm{~min}$. \\
\hline & & & $450-650^{\circ} \mathrm{C}$ & $-1.6 w t \%$ & N/A \\
\hline & & & $650-700^{\circ} \mathrm{C}$ & $-0.2 w t \%$ & N/A \\
\hline \multirow{6}{*}{952} & \multirow{6}{*}{$\begin{array}{c}3^{\circ} \mathrm{C} / \text { min to } 300^{\circ} \mathrm{C}, 2 \text { hour hold, } 5^{\circ} \mathrm{C} / \text { min to } \\
700^{\circ} \mathrm{C}\end{array}$} & \multirow{6}{*}{ Fluid Bed } & $50-120^{\circ} \mathrm{C}$ & $-2.0 w t \%$ & N/A \\
\hline & & & $120-290^{\circ} \mathrm{C}$ & $-0.7 w t \%$ & N/A \\
\hline & & & $290-300^{\circ} \mathrm{C}$ & $-3.8 w t \%$ & $20 \mathrm{~min}$. \\
\hline & & & $300^{\circ} \mathrm{C}-450^{\circ} \mathrm{C}$ & $-1.0 w t \%$ & $100 \mathrm{~min}$. \\
\hline & & & $450-610^{\circ} \mathrm{C}$ & $-0.7 w t \%$ & N/A \\
\hline & & & $610-700^{\circ} \mathrm{C}$ & $-1.0 w t \%$ & $\mathrm{~N} / \mathrm{A}$ \\
\hline \multirow{5}{*}{957} & \multirow{5}{*}{$\mid \begin{array}{c}3{ }^{\circ} \mathrm{C} / \mathrm{min} \text { to } 300^{\circ} \mathrm{C}, 2 \text { hour hold, } 5^{\circ} \mathrm{C} / \mathrm{min} \text { to } \\
700^{\circ} \mathrm{C}\end{array}$} & \multirow{5}{*}{ Fluid Bed } & $50-120^{\circ} \mathrm{C}$ & $-0.7 w t \%$ & N/A \\
\hline & & & $120-300^{\circ} \mathrm{C}$ & $-8.1 w t \%$ & $10 \mathrm{~min}$. \\
\hline & & & $300-365^{\circ} \mathrm{C}$ & $-1.2 w t \%$ & $110 \mathrm{~min}$. \\
\hline & & & $365-525^{\circ} \mathrm{C}$ & $-0.7 w t \%$ & $\mathrm{~N} / \mathrm{A}$ \\
\hline & & & $525-700^{\circ} \mathrm{C}$ & $-1.8 w t \%$ & N/A \\
\hline \multirow{6}{*}{1034} & \multirow{6}{*}{$\begin{array}{c}3^{\circ} \mathrm{C} / \mathrm{min} \text { to } 300^{\circ} \mathrm{C}, 2 \text { hour hold, } 5^{\circ} \mathrm{C} / \mathrm{min} \text { to } \\
700^{\circ} \mathrm{C}\end{array}$} & \multirow{6}{*}{ Fluid Bed } & $20-115^{\circ} \mathrm{C}$ & $-0.2 w t \%$ & $\mathrm{~N} / \mathrm{A}$ \\
\hline & & & $115-200^{\circ} \mathrm{C}$ & $-0.6 w t \%$ & $\mathrm{~N} / \mathrm{A}$ \\
\hline & & & $240-300^{\circ} \mathrm{C}$ & $-0.8 w t \%$ & $5 \mathrm{~min}$. \\
\hline & & & $300-475^{\circ} \mathrm{C}$ & $+0.3 w t \%$ & $115 \mathrm{~min}$. \\
\hline & & & $475-580^{\circ} \mathrm{C}$ & $-0.4 w t \%$ & N/A \\
\hline & & & $650-700^{\circ} \mathrm{C}$ & $-0.2 w t \%$ & N/A \\
\hline \multirow{3}{*}{1007} & \multirow{3}{*}{$3^{\circ} \mathrm{C} / \min$ to $300^{\circ} \mathrm{C}, 2$ hour hold } & \multirow{3}{*}{ GEMCO - $3 \%$ HPMC \& PEG } & $\mathrm{RT}-150^{\circ} \mathrm{C}$ & $-3.0 w t \%$ & N/A \\
\hline & & & $150-270^{\circ} \mathrm{C}$ & $-1.8 w t \%$ & N/A \\
\hline & & & $270-300^{\circ} \mathrm{C}$ & $-0.7 w t \%$ & $35 \mathrm{~min}$. \\
\hline \multirow{4}{*}{1008} & \multirow{4}{*}{$\mid \begin{array}{c}3^{\circ} \mathrm{C} / \mathrm{min} \text { to } 300^{\circ} \mathrm{C}, 2 \text { hour hold, } 5^{\circ} \mathrm{C} / \mathrm{min} \text { to } \\
700^{\circ} \mathrm{C}\end{array}$} & \multirow{4}{*}{ GEMCO } & $\mathrm{RT}-150^{\circ} \mathrm{C}$ & $-1.5 w t \%$ & N/A \\
\hline & & & $150-270^{\circ} \mathrm{C}$ & $-3.0 \mathrm{wt} \%$ & N/A \\
\hline & & & $270-300^{\circ} \mathrm{C}$ & $-0.9 w t \%$ & $120 \mathrm{~min}$. \\
\hline & & & $500-700^{\circ} \mathrm{C}$ & $-0.5 w t \%$ & N/A \\
\hline \multirow{3}{*}{1076} & \multirow{3}{*}{$3^{\circ} \mathrm{C} / \mathrm{min}$ to $300^{\circ} \mathrm{C}, 2$ hour hold } & \multirow{3}{*}{ Pin Mixer } & $\mathrm{RT}-110^{\circ} \mathrm{C}$ & $-3.4 w t \%$ & N/A \\
\hline & & & $110-300^{\circ} \mathrm{C}$ & $-8.3 w t \%$ & $20 \mathrm{~min}$. \\
\hline & & & hold@300 $@$ & $+0.2 \mathrm{wt} \%$ & 100 min. \\
\hline
\end{tabular}


APPENDIX B (Continued)

Weight Loss Data From Binder Burnout Testing Performed To Date

Phase 2 of Testing (Continued)

Granulated Materials

\begin{tabular}{|c|c|c|c|c|c|}
\hline Puck \# & Schedule Tested & Variable & $\begin{array}{c}\text { Transition } \\
\text { Temperature } \\
\text { Ranges }\end{array}$ & $\begin{array}{l}\text { Associated } \\
\text { Weight } \\
\text { Changes }\end{array}$ & $\begin{array}{l}\text { Associated } \\
\text { Hold Time* }\end{array}$ \\
\hline \multirow{5}{*}{1088} & \multirow{5}{*}{$\begin{array}{c}3^{\circ} \mathrm{C} / \mathrm{min} \text { to } 300^{\circ} \mathrm{C}, 2 \text { hour hold, } 5^{\circ} \mathrm{C} / \mathrm{min} \text { to } \\
700^{\circ} \mathrm{C}\end{array}$} & \multirow{5}{*}{ Pin Mixer } & $60-120^{\circ} \mathrm{C}$ & $-0.9 w t \%$ & N/A \\
\hline & & & $120-300^{\circ} \mathrm{C}$ & $-8.4 w t \%$ & $15 \mathrm{~min}$. \\
\hline & & & $300-400^{\circ} \mathrm{C}$ & $+0.2 w t \%$ & $105 \mathrm{~min}$. \\
\hline & & & $400-645^{\circ} \mathrm{C}$ & $-1.7 w t \%$ & $\mathrm{~N} / \mathrm{A}$ \\
\hline & & & $645-700^{\circ} \mathrm{C}$ & $-0.1 w t \%$ & $\mathrm{~N} / \mathrm{A}$ \\
\hline \multirow{5}{*}{$\begin{array}{c}\text { SR230 } \\
\mathrm{A}\end{array}$} & \multirow{5}{*}{$\begin{array}{c}3^{\circ} \mathrm{C} / \mathrm{min} \text { to } 300^{\circ} \mathrm{C}, 2 \text { hour hold, } 5^{\circ} \mathrm{C} / \mathrm{min} \text { to } \\
700^{\circ} \mathrm{C}\end{array}$} & \multirow{5}{*}{$\begin{array}{c}\text { Roll Compactor }-2.2 \% \text { HPMC \& } \\
3 \% \text { PEG }\end{array}$} & $110-270^{\circ} \mathrm{C}$ & $-1.0 w t \%$ & N/A \\
\hline & & & $270-300^{\circ} \mathrm{C}$ & $1.5 w t \%$ & $30 \mathrm{~min}$. \\
\hline & & & $300-450^{\circ} \mathrm{C}$ & $-0.5 w t \%$ & $90 \mathrm{~min}$. \\
\hline & & & $450-480^{\circ} \mathrm{C}$ & $-3.0 w t \%$ & N/A \\
\hline & & & $580-700^{\circ} \mathrm{C}$ & $-1.2 w t \%$ & N/A \\
\hline \multirow{3}{*}{ SR235 } & \multirow{3}{*}{$\begin{array}{c}3^{\circ} \mathrm{C} / \mathrm{min} \text { to } 300^{\circ} \mathrm{C}, 2 \text { hour hold, } 5^{\circ} \mathrm{C} / \mathrm{min} \text { to } \\
700^{\circ} \mathrm{C}\end{array}$} & \multirow{3}{*}{ Roll Compactor - $2.2 \%$ HPMC } & $110-240^{\circ} \mathrm{C}$ & $-0.5 w t \%$ & N/A \\
\hline & & & $240-300^{\circ} \mathrm{C}$ & $-1.2 w t \%$ & $15 \mathrm{~min}$. \\
\hline & & & $420-700^{\circ} \mathrm{C}$ & -2.0 wt\% & N/A \\
\hline \multirow{5}{*}{$\begin{array}{c}\mathrm{SR} 230 \\
\mathrm{~B}\end{array}$} & \multirow{5}{*}{$\begin{array}{c}3^{\circ} \mathrm{C} / \text { min to } 300^{\circ} \mathrm{C}, 2 \text { hour hold, } 5^{\circ} \mathrm{C} / \mathrm{min} \text { to } \\
700^{\circ} \mathrm{C}\end{array}$} & \multirow{5}{*}{$\begin{array}{c}\text { Roll Compactor }-2.2 \% \text { HPMC \& } \\
2 \% \text { PEG }\end{array}$} & $150-270^{\circ} \mathrm{C}$ & $-0.5 w t \%$ & N/A \\
\hline & & & $270-300^{\circ} \mathrm{C}$ & $-1.1 w t \%$ & $10 \mathrm{~min}$. \\
\hline & & & $410-470^{\circ} \mathrm{C}$ & $-0.3 w t \%$ & $\mathrm{~N} / \mathrm{A}$ \\
\hline & & & $470-515^{\circ} \mathrm{C}$ & $-2.1 w t \%$ & N/A \\
\hline & & & $630-700^{\circ} \mathrm{C}$ & $-0.5 w t \%$ & N/A \\
\hline \multirow{2}{*}{1059} & \multirow{2}{*}{$3^{\circ} \mathrm{C} / \mathrm{min}$ to $300^{\circ} \mathrm{C}, 2$ hour hold } & \multirow{2}{*}{$\begin{array}{c}\text { Roll Compactor - } 2.2 \% \text { HPMC \& } \\
0.5 \% \text { PEG }\end{array}$} & $110-240^{\circ} \mathrm{C}$ & $-0.7 w t \%$ & N/A \\
\hline & & & $240-300^{\circ} \mathrm{C}$ & $-1.3 w t \%$ & 24 min. \\
\hline \multirow{6}{*}{1061} & \multirow{6}{*}{$\begin{array}{c}3^{\circ} \mathrm{C} / \mathrm{min} \text { to } 300^{\circ} \mathrm{C}, 2 \text { hour hold, } 5^{\circ} \mathrm{C} / \mathrm{min} \text { to } \\
700^{\circ} \mathrm{C}\end{array}$} & \multirow{6}{*}{$\begin{array}{c}\text { Roll Compactor - } 2.2 \% \text { HPMC \& } \\
0.5 \% \text { PEG }\end{array}$} & $90-240^{\circ} \mathrm{C}$ & $-0.8 w t \%$ & N/A \\
\hline & & & $240-300^{\circ} \mathrm{C}$ & $-1.2 w t \%$ & $24 \mathrm{~min}$. \\
\hline & & & $300-460^{\circ} \mathrm{C}$ & $-0.2 w t \%$ & 96 min. \\
\hline & & & $460-510^{\circ} \mathrm{C}$ & $-1.3 w t \%$ & $\mathrm{~N} / \mathrm{A}$ \\
\hline & & & $510-600^{\circ} \mathrm{C}$ & $-0.4 w t \%$ & N/A \\
\hline & & & $600-700^{\circ} \mathrm{C}$ & $-1.1 w t \%$ & $\mathrm{~N} / \mathrm{A}$ \\
\hline
\end{tabular}

*Hold times represent the time at the upper temperature or the time at temperature before change occurs. 
APPENDIX B (Continued)

Weight Loss Data From Binder Burnout Testing Performed To Date

Phase 3 of Testing

GEMCO Granulated Material (1\% HPMC) with Binder Burnout Process Optimization

\begin{tabular}{|c|c|c|c|c|c|}
\hline Puck \# & Schedule Tested & Variable & $\begin{array}{c}\text { Transition } \\
\text { Temperature } \\
\text { Ranges } \\
\end{array}$ & $\begin{array}{c}\text { Associated } \\
\text { Weight Changes }\end{array}$ & $\begin{array}{c}\text { Associated Hold } \\
\text { Time* }\end{array}$ \\
\hline \multirow{2}{*}{1107} & $3^{\circ} \mathrm{C} / \mathrm{min}$ to & \multirow{2}{*}{ Dehydration hold } & $50-100^{\circ} \mathrm{C}$ & $-0.5 w t \%$ & N/A \\
\hline & $160^{\circ} \mathrm{C}, 1$ hour & & $100-160^{\circ} \mathrm{C}$ & $-5.5 w t \%$ & $60 \mathrm{~min}$. \\
\hline \multirow{2}{*}{1108} & $3^{\circ} \mathrm{C} / \mathrm{min}$ to & \multirow{2}{*}{ Dehydration hold } & $50-100^{\circ} \mathrm{C}$ & $-0.5 \mathrm{wt} \%$ & $\mathrm{~N} / \mathrm{A}$ \\
\hline & $140^{\circ} \mathrm{C}, 2$ hour & & $100-140^{\circ} \mathrm{C}$ & $-7.7 w t \%$ & 120 min. \\
\hline \multirow{2}{*}{1112} & $3^{\circ} \mathrm{C} / \mathrm{min}$ to & \multirow{2}{*}{ Dehydration hold } & $50-100^{\circ} \mathrm{C}$ & $-0.5 \mathrm{wt} \%$ & N/A \\
\hline & $160^{\circ} \mathrm{C}, 2$ hour & & $100-160^{\circ} \mathrm{C}$ & $-9.2 w t \%$ & $120 \mathrm{~min}$. \\
\hline \multirow{2}{*}{1113} & $3^{\circ} \mathrm{C} / \mathrm{min}$ to & \multirow{2}{*}{ Dehydration hold } & $50-100^{\circ} \mathrm{C}$ & $-0.5 w t \%$ & N/A \\
\hline & $180^{\circ} \mathrm{C}, 1$ hour & & $100-180^{\circ} \mathrm{C}$ & $-7.7 w t \%$ & $60 \mathrm{~min}$. \\
\hline \multirow{2}{*}{1118} & $3^{\circ} \mathrm{C} / \mathrm{min}$ to & \multirow{2}{*}{ Dehydration hold } & $50-100^{\circ} \mathrm{C}$ & $-0.5 \mathrm{wt} \%$ & N/A \\
\hline & $180^{\circ} \mathrm{C}, 2$ hour & & $100-180^{\circ} \mathrm{C}$ & $-9.3 w t \%$ & $100 \mathrm{~min}$. \\
\hline \multirow{2}{*}{1132} & $3^{\circ} \mathrm{C} / \mathrm{min}$ to & \multirow{2}{*}{ Dehydration hold } & $50-100^{\circ} \mathrm{C}$ & $-0.5 w t \%$ & $\mathrm{~N} / \mathrm{A}$ \\
\hline & $180^{\circ} \mathrm{C}, 4$ hour & & $100-180^{\circ} \mathrm{C}$ & $-10.3 w t \%$ & $100 \mathrm{~min}$. \\
\hline \multirow{5}{*}{1133} & \multirow{5}{*}{$\begin{array}{c}3^{\circ} \mathrm{C} / \mathrm{min} \text { to } \\
180^{\circ} \mathrm{C}, 2 \text { hour } \\
\text { hold, } 3^{\circ} \mathrm{C} / \text { min to } \\
440^{\circ} \mathrm{C}\end{array}$} & \multirow{5}{*}{ Binder hold } & $\mathrm{RT}-60^{\circ} \mathrm{C}$ & $-0.2 w t \%$ & N/A \\
\hline & & & $60-180^{\circ} \mathrm{C}$ & $-2.7 \mathrm{wt} \%$ & $80 \mathrm{~min}$. \\
\hline & & & $220-260^{\circ} \mathrm{C}$ & $-0.1 w t \%$ & N/A \\
\hline & & & $260-315^{\circ} \mathrm{C}$ & $-0.2 w t \%$ & N/A \\
\hline & & & $315-400^{\circ} \mathrm{C}$ & $-0.1 w \mathrm{t} \%$ & N/A \\
\hline \multirow{5}{*}{1134} & \multirow{5}{*}{$\begin{array}{c}3^{\circ} \mathrm{C} / \mathrm{min} \text { to } \\
180^{\circ} \mathrm{C}, 2 \text { hour } \\
\text { hold, } 3^{\circ} \mathrm{C} / \text { min to } \\
700^{\circ} \mathrm{C}\end{array}$} & \multirow{5}{*}{ Binder hold } & $50-100^{\circ} \mathrm{C}$ & $-0.5 \mathrm{wt} \%$ & N/A \\
\hline & & & $100-180^{\circ} \mathrm{C}$ & $-9.5 \mathrm{wt} \%$ & 100 min. \\
\hline & & & $220-280^{\circ} \mathrm{C}$ & $-0.4 \mathrm{wt} \%$ & $\mathrm{~N} / \mathrm{A}$ \\
\hline & & & $470-580^{\circ} \mathrm{C}$ & $-0.8 w t \%$ & N/A \\
\hline & & & $580-700^{\circ} \mathrm{C}$ & $-0.2 w t \%$ & N/A \\
\hline \multirow{3}{*}{1158} & $3^{\circ} \mathrm{C} / \mathrm{min}$ to & \multirow{3}{*}{$\begin{array}{c}\text { Binder hold with } \\
\text { ramp rate }\end{array}$} & $\mathrm{RT}-75^{\circ} \mathrm{C}$ & $-0.5 \mathrm{wt} \%$ & N/A \\
\hline & $180^{\circ} \mathrm{C}, 2$ hour & & $75-180^{\circ} \mathrm{C}$ & $-9.3 w t \%$ & $100 \mathrm{~min}$. \\
\hline & hold, $0.5^{\circ} \mathrm{C} / \mathrm{min}$ & & $200-240^{\circ} \mathrm{C}$ & $-0.4 \mathrm{wt} \%$ & N/A \\
\hline \multirow{3}{*}{1159} & $3^{\circ} \mathrm{C} / \mathrm{min}$ to & \multirow{3}{*}{$\begin{array}{c}\text { Binder hold with } \\
\text { ramp rate }\end{array}$} & $40-150^{\circ} \mathrm{C}$ & $-0.5 \mathrm{wt} \%$ & N/A \\
\hline & $180^{\circ} \mathrm{C}, 2$ hour & & $150-180^{\circ} \mathrm{C}$ & $-8.1 w t \%$ & $90 \mathrm{~min}$. \\
\hline & hold, $0.5^{\circ} \mathrm{C} / \mathrm{min}$ & & $220-250^{\circ} \mathrm{C}$ & $-0.4 \mathrm{wt} \%$ & N/A \\
\hline \multirow{4}{*}{1160} & $3^{\circ} \mathrm{C} / \mathrm{min}$ to & \multirow{4}{*}{$\begin{array}{c}\text { Ramp rate } \\
\text { through burnout }\end{array}$} & $50-180^{\circ} \mathrm{C}$ & $-10.0 \mathrm{wt} \%$ & $90 \mathrm{~min}$. \\
\hline & $180^{\circ} \mathrm{C}, 2$ hour & & $200-240^{\circ} \mathrm{C}$ & $-0.4 w t \%$ & N/A \\
\hline & hold, $0.5^{\circ} \mathrm{C} / \mathrm{min}$ & & $380-480^{\circ} \mathrm{C}$ & $-0.8 \mathrm{wt} \%$ & N/A \\
\hline & to $700^{\circ} \mathrm{C}$ & & $580-700^{\circ} \mathrm{C}$ & $-1.6 \mathrm{wt} \%$ & N/A \\
\hline \multirow{5}{*}{1162} & \multirow{5}{*}{$\begin{array}{c}3^{\circ} \mathrm{C} / \mathrm{min} \text { to } \\
180^{\circ} \mathrm{C}, 2 \text { hour } \\
\text { hold, } 1^{\circ} \mathrm{C} / \text { min to } \\
700^{\circ} \mathrm{C}\end{array}$} & \multirow{5}{*}{$\begin{array}{c}\text { Ramp rate } \\
\text { through burnout }\end{array}$} & $50-95^{\circ} \mathrm{C}$ & $-0.4 w t \%$ & N/A \\
\hline & & & $95-180^{\circ} \mathrm{C}$ & $-10.0 \mathrm{wt} \%$ & $90 \mathrm{~min}$. \\
\hline & & & $240-260^{\circ} \mathrm{C}$ & $-0.4 w t \%$ & N/A \\
\hline & & & $420-500^{\circ} \mathrm{C}$ & $-0.7 \mathrm{wt} \%$ & N/A \\
\hline & & & $620-700^{\circ} \mathrm{C}$ & $-0.9 \mathrm{wt} \%$ & N/A \\
\hline
\end{tabular}


APPENDIX B (Continued)

Weight Loss Data From Binder Burnout Testing Performed To Date Phase 3 of Testing (Continued)

GEMCO Granulated Material (1\% HPMC) with Binder Burnout Process Optimization

\begin{tabular}{|c|c|c|c|c|c|}
\hline Puck \# & Schedule Tested & Variable & $\begin{array}{c}\text { Transition } \\
\text { Temperature } \\
\text { Ranges } \\
\end{array}$ & $\begin{array}{c}\text { Associated } \\
\text { Weight Changes }\end{array}$ & $\begin{array}{c}\text { Associated Hold } \\
\text { Time* }\end{array}$ \\
\hline \multirow{4}{*}{1165} & \multirow{4}{*}{$\begin{array}{c}3^{\circ} \mathrm{C} / \mathrm{min} \text { to } \\
180^{\circ} \mathrm{C}, 2 \text { hour } \\
\text { hold, } 1^{\circ} \mathrm{C} / \mathrm{min} \text { to } \\
400^{\circ} \mathrm{C}, 3^{\circ} \mathrm{C} / \mathrm{min}\end{array}$} & \multirow{4}{*}{$\begin{array}{c}\text { Ramp rate } \\
\text { through burnout }\end{array}$} & $60-180^{\circ} \mathrm{C}$ & $-10.0 w t \%$ & $90 \mathrm{~min}$. \\
\hline & & & $240-260^{\circ} \mathrm{C}$ & $-0.4 w t \%$ & $\mathrm{~N} / \mathrm{A}$ \\
\hline & & & $450-540^{\circ} \mathrm{C}$ & $-0.5 w t \%$ & N/A \\
\hline & & & $540-700^{\circ} \mathrm{C}$ & $-1.8 w t \%$ & N/A \\
\hline \multirow{5}{*}{1170} & \multirow{5}{*}{$\begin{array}{c}3^{\circ} \mathrm{C} / \mathrm{min} \text { to } \\
180^{\circ} \mathrm{C}, 2 \text { hour } \\
\text { hold, } 1^{\circ} \mathrm{C} / \mathrm{min} \text { to } \\
600^{\circ} \mathrm{C}, 2 \text { hour } \\
\text { hold }\end{array}$} & \multirow{5}{*}{$\begin{array}{l}\text { Ramp rate and } \\
\text { Second hold }\end{array}$} & RT $-50^{\circ} \mathrm{C}$ & $-0.7 w t \%$ & $\mathrm{~N} / \mathrm{A}$ \\
\hline & & & $50-180^{\circ} \mathrm{C}$ & $-9.1 w t \%$ & $90 \mathrm{~min}$. \\
\hline & & & $240-260^{\circ} \mathrm{C}$ & $-0.3 w t \%$ & N/A \\
\hline & & & $420-505^{\circ} \mathrm{C}$ & $-0.7 w t \%$ & N/A \\
\hline & & & $580-600^{\circ} \mathrm{C}$ & $-0.6 w t \%$ & $120 \mathrm{~min}$. \\
\hline \multirow{5}{*}{1183} & \multirow{5}{*}{$\begin{array}{c}3^{\circ} \mathrm{C} / \mathrm{min} \text { to } \\
180^{\circ} \mathrm{C}, 2 \text { hour } \\
\text { hold }, 1^{\circ} \mathrm{C} / \mathrm{min} \text { to } \\
700^{\circ} \mathrm{C}, 2 \text { hour } \\
\text { hold }\end{array}$} & \multirow{5}{*}{$\begin{array}{l}\text { Ramp rate and } \\
\text { Second hold }\end{array}$} & $20-50^{\circ} \mathrm{C}$ & $-0.3 w t \%$ & $\mathrm{~N} / \mathrm{A}$ \\
\hline & & & $50-180^{\circ} \mathrm{C}$ & $-9.6 w t \%$ & $90 \mathrm{~min}$. \\
\hline & & & $220-240^{\circ} \mathrm{C}$ & $-0.3 w t \%$ & $\mathrm{~N} / \mathrm{A}$ \\
\hline & & & $440-540^{\circ} \mathrm{C}$ & $-0.8 w t \%$ & $\mathrm{~N} / \mathrm{A}$ \\
\hline & & & $540-700^{\circ} \mathrm{C}$ & $-1.4 w t \%$ & $120 \mathrm{~min}$. \\
\hline \multirow{5}{*}{1230} & \multirow{5}{*}{$\begin{array}{c}3^{\circ} \mathrm{C} / \mathrm{min} \text { to } \\
180^{\circ} \mathrm{C}, 2 \text { hour } \\
\text { hold, } 1^{\circ} \mathrm{C} / \mathrm{min} \text { to } \\
700^{\circ} \mathrm{C}, 3 \text { hour } \\
\text { hold }\end{array}$} & \multirow{5}{*}{$\begin{array}{l}\text { Ramp rate and } \\
\text { Second hold }\end{array}$} & $\mathrm{RT}-100^{\circ} \mathrm{C}$ & $-0.5 w t \%$ & N/A \\
\hline & & & $100-180^{\circ} \mathrm{C}$ & $-9.4 w t \%$ & $100 \mathrm{~min}$. \\
\hline & & & $180-245^{\circ} \mathrm{C}$ & $-0.1 w t \%$ & $20 \mathrm{~min}$. \\
\hline & & & $400-525^{\circ} \mathrm{C}$ & $-1.0 w t \%$ & $\mathrm{~N} / \mathrm{A}$ \\
\hline & & & $590-700^{\circ} \mathrm{C}$ & $-0.7 w t \%$ & N/A \\
\hline \multirow{5}{*}{1232} & \multirow{5}{*}{$\begin{array}{c}3^{\circ} \mathrm{C} / \mathrm{min} \text { to } \\
180^{\circ} \mathrm{C}, 2 \text { hour } \\
\text { hold, } 1^{\circ} \mathrm{C} / \mathrm{min} \text { to } \\
400^{\circ} \mathrm{C}, 5^{\circ} \mathrm{C} / \mathrm{min} \\
\text { to } 600^{\circ} \mathrm{C}\end{array}$} & \multirow{5}{*}{$\begin{array}{c}\text { Ramp rate } \\
\text { through burnout }\end{array}$} & $\mathrm{RT}-80^{\circ} \mathrm{C}$ & $-0.3 w t \%$ & N/A \\
\hline & & & $80-180^{\circ} \mathrm{C}$ & $-8.7 w t \%$ & $90 \mathrm{~min}$. \\
\hline & & & $240-260^{\circ} \mathrm{C}$ & $-0.2 \mathrm{wt} \%$ & $\mathrm{~N} / \mathrm{A}$ \\
\hline & & & $450-610^{\circ} \mathrm{C}$ & $-1.2 w t \%$ & $\mathrm{~N} / \mathrm{A}$ \\
\hline & & & $640-700^{\circ} \mathrm{C}$ & $-1.9 w \mathrm{t} \%$ & $180 \mathrm{~min}$. \\
\hline
\end{tabular}

*Hold times represent the time at the upper temperature or the time at temperature before change occurs. 